Cómo citar este trabajo: Aguilar Lucato, R. (2021). Functional and correlation analysis between morphology and urban land uses in Madrid, Spain. Boletín de la Asociación de Geógrafos Españoles, (89). https://doi.org/10.21138/bage.3031

\title{
Análisis funcional y de correlaciones entre morfología y usos \\ del suelo urbano en Madrid (España)
}

\author{
Functional and correlation analysis between morphology \\ and urban land uses in Madrid, Spain
}

\author{
Ramón Aguilar Lucato \\ rlucatodeaguilar@gmail.com \\ Departamento de Urbanística y Ordenación del Territorio (DUyOT) \\ Universidad Politécnica de Madrid (España)
}

\section{Resumen}

A fin de que se verificara como se refleja en el presente una producción históricamente desigual del espacio urbano madrileño se eligieron quince muestras de tejidos urbanos, tres en cada una de las clases morfológicas discutidas por Rodríguez-Tarduchy (2011), cada cual en una distinta realidad socioeconómica en el marco de su clase (inferior, intermediaria y superior). La investigación se basó, para cada tejido, en el análisis de 22 indicadores morfológicos y veinte funcionales y posibilitó conclusiones cuantitativas sobre las variaciones de carácter funcional dentro de una misma clase morfológica, pero en distintos paisajes sociales, bien como entre distintas clases, considerando un amplio espectro del espacio urbano madrileño. Al final, todos los indicadores funcionales fueron correlacionados entre sí, amén de estos con los morfológicos, de modo a que fuera contestada la indagación sobre cómo, con base en la muestra estudiada, las formas y las funciones urbanas se influyen. Se obtuvieron correlaciones consistentes entre 
densidades urbanas, edad media de la edificación, diversidad de funciones urbanas, valor del suelo, diversidad social, accesibilidad por transporte público y dimensión media de la manzana.

Palabras clave: producción desigual del espacio urbano; usos del suelo urbano; diagrama de mezcla de usos del suelo; morfología urbana; geografía urbana de Madrid.

\begin{abstract}
In order to verify how a historically uneven production of Madrid's urban space is reflected in the present, fiffeen samples of urban fabrics were chosen, three in each of the morphological classes discussed by Rodríguez-Tarduchy (2011), each in a different socioeconomic reality within the framework of its class (inferior, intermediate and superior). The research was based, for each fabric, on the analysis of 22 morphological and twenty functional indicators and made possible quantitative conclusions about the functional variations within the same morphological class, but in different social landscapes, as well as between different classes, considering a broad spectrum of Madrid's urban space. In the end, all the functional indicators were correlated with each other, in addition to the morphological ones, so that the inquiry about how, based on the sample studied, urban forms and functions influence each other was answered. Consistent correlations were obtained between urban densities, average age of the building, diversity of urban functions, value of land, social diversity, accessibility by public transport and average size of the block.
\end{abstract}

Key words: uneven production of urban space; urban land uses; mixed land use diagram; urban morphology; urban geography of Madrid.

\title{
1 Introducción
}

Este artículo relata los resultados de una investigación sobre la producción social del espacio urbano de Madrid y su impronta en términos de conformación de morfologías dispares de acuerdo con el momento histórico de génesis del tejido urbano y según su apropiación por distintos grupos socioeconómicos. Se empieza con una breve síntesis sobre la producción desigual de las ciudades en el marco del sistema capitalista, considerando que los espacios urbanos se desarrollan como consecuencia de la búsqueda permanente por la apropiación de ganancias proporcionadas por rentas derivadas de la transformación del suelo (Capel Saez, 1975; Harvey, 1975; 1982a; Corrêa, 1989; Abramo, 2009). En seguida se discute como la ciudad de Madrid se ha expandido desde el derrumbe de sus murallas en el siglo XIX a partir de 
la perspectiva de los comentados procesos especulativos. Esas discusiones conforman el marco teórico desde el cual se alcanza el objetivo de este trabajo, es decir, analizar las correlaciones entre una morfología urbana desigualmente producida y las funciones urbanas (o usos del suelo), bien como entre los indicadores funcionales. Se busca, así, comprender como determinados rasgos morfológicos y funcionales contribuyen para explicar la organización actual de Madrid. El análisis morfológico se basa en la propuesta de Pont \& Haupt (2009), mientras el funcional en el método planteado por Van den Hoek (2010) y Solís Trapero et al. (2019). Se subraya que el término "morfológico" es aquí utilizado para referirse a las formas físicas, de modo a diferenciarlas de las funciones urbanas, a distinción, por tanto, del concepto amplio de Morfología urbana propuesto por Conzen (1960).

Corrêa (1989) informa que la ciudad capitalista deriva de la acción de una multiplicidad de agentes sociales y que algunos disponen de poder político y económico para darle una forma que favorezca la obtención de ganancias derivadas de la especulación sobre el suelo y sobre la inversión en productos inmobiliarios. Otros agentes, aunque cardinales en la materialización del espacio urbano, poseen un influjo inferior sobre la definición de los espacios que se les puede ser destinado. Es el caso de las clases con rendimientos mediano bajos a bajos, cuyas viviendas son marginadas a las zonas preteridas por el primer grupo.

Las clases medias y altas, en contraste, cuentan con una función fundamental en la producción de formas y procesos urbanos una vez que ofrecen la liquidez necesaria para la sustentación del proceso especulativo de valorización de suelos periurbanos, seguida por la difusión de la orilla periférica en sectores ennoblecidos de expansión urbana, o aún, constituyen el mercado al que se destinan los innovadores productos inmobiliarios formados a partir de la reconversión de casas "deterioradas" en zonas pericentrales sujetas a mecanismos de gentrificación (Sequera Fernández, 2013). Ambos procesos son seguidos por la obsolescencia programada llevada a término por los promotores inmobiliarios, que permanentemente deben seducir esa clase solvente - por medio de innovaciones inmobiliarias - a cambiar de vivienda lo a invertir en residencias secundarias), desvalorizando ciertos sectores de la ciudad y valorizando (o revalorizando) otros (Abramo, 2009). El proceso de expansión de las grandes urbes capitalistas modernas sostiene, de este modo, una exclusión espacial que se acentúa con el tiempo y repercute en la fragmentación urbana, pues una mayoría creciente de familias tiene dificultad en soportar los costes progresivos del suelo urbano. 
Este mecanismo de valorización del suelo periférico y de extensión de la ciudad como modo de absorción del capital excedente en otros sectores económicos (Harvey, 1982b) ha conducido en las últimas cuatro décadas a la generación en España de periferias difusas que han respondido por la génesis de morfologías duales, es decir, simultáneamente densas -en el centro y en los barrios consolidados- y dispersas -en los nuevos anillos periféricos, conformados principalmente por viviendas unifamiliares y bloques exentos en altura y accesibles esencialmente por modos privados de desplazamiento- (López de Lucio, 2003; Roch Peña, 2009; Naredo, 2010; Rubiera Morollón et al., 2016).

Madrid, en seguida al derrumbe, en mediados del siglo XIX, de las murallas que circunscribían su casco histórico, ha sufrido un permanente proceso de expansión bajo formas que se han caracterizado por una creciente segregación socioespacial y una progresiva disminución de densidades (Rubiera Morollón et al., 2016). Si los primeros planes de expansión, aún en los años decimonónicos con los ensanches de Carlos María de Castro, eran definidos por la permisividad a una cierta mezcla social inicial, pronto se constituyeron ejes de crecimiento fundamentados en la capacidad financiera de las familias. Así, los sectores norte -eje de la Castellana- y noroeste -calle de la Princesa, Ciudad Universitaria y El Pardo- fueron apropiados por grupos sociales acomodados, a la vez que los ámbitos meridionales (suroeste, sur y sureste) de la capital española fueron progresivamente ocupados por familias de ingresos bajos a medios (Brandis, 1983; Tamayo Palacios, 2011).

Sin embargo, con independencia de la tipología adoptada y del grupo social al que sería destinada la promoción, los desarrollos que se difundieron después de la Guerra Civil fueron definidos por una adhesión generalizada a las ideas del modernismo funcionalista (bajo formas de barrios de viviendas unifamiliares o, principalmente, de polígonos de bloques plurifamiliares). Estas promociones se fijan por las bajas densidades edificatorias, desarticulación de elementos urbanísticos tradicionales y producción seriada sin desvelo a un plan de urbanización bien articulado, además de valerse de técnicas y materiales de bajo estándar, justificados por la necesidad de construirse muchas viviendas rápidamente para albergar una población migrante que creció explosivamente entre finales de la contienda y la década de 1970. Estas circunstancias posibilitaron la conformación de grandes corporaciones inmobiliarias que pasaron a contar con un poder económico y político expansivo y que dejaban una huella en la ciudad caracterizada por promociones marcadas por dimensiones y grado de homogeneidad crecientes, desconectadas de su entorno, dependientes del vehículo privado y sin atención a aspectos urbanísticos que garantizaran la mezcla funcional y un enriquecimiento de usos del 
suelo que posibilitaran la génesis de una vida urbana local (Brandis, 1983; Panerai et al., 1986; Rodríguez-Chumillas, 2001).

En ese sentido, Blanco \& Subirats (2012) informan que tras el Plan de Estabilización de 1959, las grandes ciudades españolas acumularan industrias, servicios y nuevos residentes, sin que esa rápida transformación fuera acompañada por políticas públicas consistentes. Los migrantes se establecían como podían, en cualquier enclave que encontraran para (auto)construir sus precarias viviendas. El Estado autoritario optó por un "urbanismo de mínimos" para afrontar ese nuevo reto, por el que eran construidos polígonos de viviendas de escaso estándar en barrios periféricos, sin que hubiera cualquier tipo de participación comunitaria en su planteamiento. Los pocos ayuntamientos que disponían de alguna capacidad ejecutiva para desplegar políticas mínimamente complejas sufrían con el control central de sus programas y ejecuciones. Alguacil et al. (2011), de igual modo, en referencia específica a Madrid, informan que durante el franquismo existía un anhelo de plena concentración de los espacios de decisión en la capital, de modo a convertirla en una metrópoli moderna, suceso que resultó en una serie de programas y actuaciones, aunque exentos de una acción integrada asociada a un proceso de reflexión coherente.

A partir de mediados de los años 1980, hasta la crisis de 2008, España experimentó una fase de fuerte crecimiento económico, que, a distinción de la expansión precedente, no fue basado en la industria, pero en la ascendiente significancia del negocio inmobiliario y de producción de viviendas e infraestructuras. Según Naredo (2010), desde entonces la construcción se ha erigido en la auténtica industria nacional, con una participación en la estructura económica muy superior a la media europea. Justamente en ese momento, de acuerdo con Blanco \& Subirats (2012), las ciudades españolas ya no son percibidas como centros manufactureros, pero como polos de servicios avanzados, lo que motivó el traslado de las industrias a las segundas coronas metropolitanas, induciendo - paralelamente a la expansión demográfica- la difusión de la mancha urbanizada.

El cambio político a partir de la segunda mitad de los 1970 supuso la puesta en marcha de un auténtico programa de reconstrucción urbana, mediante la plasmación de propuestas políticas lideradas por los movimientos vecinales, que desde muchos años antes luchaban por dotar los polígonos residenciales periféricos de servicios públicos y de un entorno urbanístico olvidados por el régimen franquista (Blanco \& Subirats, 2012). En Madrid, los años ochenta, particularmente, fueron caracterizados por ayuntamientos socialistas que, de acuerdo con 
Alguacil et al. (2011), evolucionaron de la movilización y participación popular -culminados en el Plan General de Ordenación Urbana de Madrid (PGOUM) de 1985- a la institucionalización y un cierto "enfriamiento" de los movimientos sociales, conformando un período de mezclas paradójicas, como entre políticas sociales comprensivas y acciones públicas que respaldaban la exclusión.

El PGOUM de 1985, flexibilizado en gran medida por el Plan de 1997 (Tomàs, 2011), merece ser destacado por su pionerismo en constatar el agotamiento de los dogmas del movimiento moderno. Ese Plan proponía la extensión de la ciudad por medio del rescate de formas pre modernistas que destacaban la continuidad orgánica del tejido, una combinación más equilibrada entre espacios libres y construidos y un sistema viario más armonioso con la escala humana, evitándose las rupturas que suponen torres aisladas y una red viaria rígida y jerarquizada. La masa edificada volvió a recibir protagonismo y las áreas libres perdieron centralidad, pasando a actuar como elementos de subsidiariedad al construido. La estructura de manzanas, el parcelario y las alineaciones fueron rescatadas y abandonado el ideal modernista de baja densidad, en consecuencia de la creciente percepción de que la densificación generaría mayor posibilidad de usos urbanos, de dinamización de la ciudad y de reducción del sentido de aislamiento entre personas (López de Lucio, 1995).

Posteriormente, en los últimos años del siglo, y tras la resolución de carencias básicas heredadas de fases históricas anteriores, los gobiernos locales empiezan a operar con la idea de estrategia urbana. Madrid, en términos de Alguacil et al. (2011), se convierte en una ciudad global y desempeña un papel clave como nodo relacional entre España y el mundo, careciendo, simultáneamente, de capacidad para controlar la expansión y agregar a sus políticas criterios de sostenibilidad socioambiental.

Estas nuevas demandas, sin embargo, se van tornando más complejas y exigiendo un cupo creciente de los presupuestos locales, hecho admisible mientras duró la fiebre especulativa en torno a la producción inmobiliaria y del espacio construido, pero que llevó, con el estallido de la burbuja en 2007/2008, a muchos gobiernos locales a enfrentar una extensa agenda de servicios con una capacidad de obtención de recursos sensiblemente reducida (Blanco \& Subirats, 2012). En este momento proliferan en España los discursos pro austeridad de matriz neoliberal, que intentan culpabilizar los más vulnerables e individualizar las responsabilidades por su infortunio, de modo a, en una condición de escasez de recursos, garantizar su fluidez a los compromisos establecidos por los distintos gobiernos junto a constructoras y entidades 
financieras, suceso que, inevitablemente, conlleva a la mercantilización de servicios y personas y a un debilitamiento de los derechos sociales logrados en los últimos decenios (Blanco \& Subirats, 2012). En otros términos, la crisis económica ha puesto en manifiesto la debilidad del modelo globalizador perseguido por Madrid desde los años 1990, basado en la exacerbación constructiva, endeudamiento y restricciones en políticas sociales y medioambientales, lo que se ha plasmado en el territorio por medio de una profundizada segregación socioespacial (Alguacil et al., 2011).

De este modo, la exclusión es el leitmotiv que talla la morfología y los usos del espacio urbano en la ciudad capitalista, particularmente la española. La nueva orientación de producción inmobiliaria para venta, en sustitución al alquiler, produce una ciudad fragmentada en sectores homogéneos, mutuamente excluyentes, y refuerzan la plasmación de un espacio urbano progresivamente más segregado. La población, el empleo, el comercio, el ocio y los grandes equipamientos se están descentralizando a un ritmo sin precedentes. Los antiguos paisajes urbanos compactos y heterogéneos son complementados por una profusión de fragmentos especializados, homogéneos y de baja densidad. Estos modelos no han hecho ciudad, sino urbanizaciones que carecen de complejidad urbana (Naredo, 2010). Así, las grandes ciudades españolas -y sobre todo Madrid- han perdido su antigua referencia de ciudad mediterránea compacta y se han transfigurado en el escenario de una polarización entre centros, ensanches y extrarradios consolidados densos (en ocasiones extremamente densos) y periferias difusas y discontinuas que se disuelven por los términos municipales vecinos (Rubiera Morollón et al., 2016).

\section{Metodología}

El análisis funcional y de correlaciones entre forma y funciones urbanas en la capital española fue desarrollado con base en quince muestras de tejidos urbanos elegidos de acuerdo con sugerencia de Pont \& Haupt (2009), y a partir de la clasificación morfológica de RodríguezTarduchy (2011), conforme se detalla a continuación. En seguida se procedió al análisis de la forma física y de los usos del espacio, con base en indicadores de formas y usos del suelo urbano. Para tanto, catorce indicadores morfológicos y trece funcionales fueron correlacionados de modo a contestarse cómo, en el caso madrileño, se corresponden formas y funciones urbanas. 


\subsection{Densidad y forma urbana}

Para Pont \& Haupt (2009) la densidad urbana contiene información valiosa sobre la forma y el performance del ambiente construido, consiguiendo articular de modo efectivo el cuantitativo y el cualitativo por medio de un método que relacione las intensidades constructivas con la forma urbana y los distintos usos y potencialidades (o performances) que le son asociadas.

La elección del área de estudio suele ser problemática, pues en la medida que se disminuye la escala espacial, el montante de suelo no construido, ocupado por vías de tráfico, ferrocarriles, áreas verdes y espacios institucionales también asciende en términos relativos, conllevando a una reducción en la densidad mensurada. Pont \& Haupt (2009) informan que son tres los métodos para la selección del área: según los límites administrativos; de acuerdo con demarcaciones proyectadas arbitrariamente; o según bordes generados en respeto a características morfológicas homogéneas.

En el presente trabajo se optó por el tercer modo, pues, aunque se generen áreas de dimensiones variadas, se pueden arbitrar los límites de modo a garantizar un grado de homogeneidad morfológica adecuado a las finalidades de la investigación, evitándose -como suele ocurrir con los dos primeros métodos- la existencia de áreas excepcionalmente vastas de espacios libres o usos institucionales, que sesgan los valores y perjudican las comparaciones con otros sectores. Esta área relativamente homogénea en términos morfológicos constituye lo que Pont \& Haupt (2009) Ilaman por tejido urbano (urban fabric en el original), es decir, "(...) una colección de manzanas, bien como de la red viaria que las circunscriben y es requerida para accederlas (...) (2009, p. 91, traducción libre).

Para la presente investigación fueron seleccionados quince tejidos urbanos, tres en cada una entre las cinco clases morfológicas predominantemente residenciales apuntadas por RodríguezTarduchy (2011), es decir, casco histórico, ensanches, viviendas unifamiliares, bloques exentos y nuevos ensanches. Estas son representativas de las innovaciones que se han generado desde mediados del siglo XIX (excepto el casco) en los modos de diseñarse y producirse las grandes ciudades españolas. La elección de las áreas de estudio se basó en el precio medio relativo de la vivienda $\left(€ / \mathrm{m}^{2}\right)$, de modo a que en cada clase morfológica se abarcaran tejidos en los barrios con el mínimo, medio y máximo valor de suelo, de acuerdo con datos más recientes (2015) fornecidos por las Áreas de Información Estadística del Ayuntamiento de Madrid (2018b). De este modo se procuró, con base en un número limitado de sectores urbanos, implicar de la 
forma más amplia posible la diversa realidad morfológica y socioeconómica del municipio de Madrid.

La Tabla 1 identifica y define los indicadores morfológicos basados en la densidad urbana, conforme Pont \& Haupt (2009), además de exponer sus métodos de cálculo.

Tabla 1. Indicadores morfológicos propuestos por Pont y Haupt (2009)

\begin{tabular}{|c|c|c|c|c|}
\hline Indicador & Sigla & Descripción & Fórmula & Unidad \\
\hline $\begin{array}{l}\text { Índice de } \\
\text { Edificabilidad } \\
\text { Bruta }\end{array}$ & FSI & $\begin{array}{l}\text { Determinada por la ratio entre la totalidad del área construida y } \\
\text { el área del suelo ocupada por la edificación. Internacionalmente } \\
\text { se la conoce por Floor Space Index (FSI), mientras en España } \\
\text { coincide con el concepto de edificabilidad bruta. }\end{array}$ & $\mathrm{FSI}=\mathrm{F} / \mathrm{A}$ & / \\
\hline $\begin{array}{l}\text { Índice de } \\
\text { Ocupación } \\
\text { Bruta }\end{array}$ & GSI & $\begin{array}{l}\text { Internacionalmente denominada Ground Space Index (GSI), es la } \\
\text { relación entre los suelos construidos y los no construidos, } \\
\text { mediante el área proyectada de la construcción sobre el suelo } \\
\text { dividida por el área total del espacio considerado. }\end{array}$ & $\mathrm{GSI}=\mathrm{B} / \mathrm{A}$ & / \\
\hline $\begin{array}{l}\text { Altura media } \\
\text { de la } \\
\text { edificación }\end{array}$ & L & Número medio de plantas de los edificios, o Layers (L). & $\begin{array}{c}\mathrm{L}=\mathrm{FSI} / \mathrm{GSI} \\
\quad \mathrm{O} \\
\mathrm{L}=\mathrm{F} / \mathrm{B}\end{array}$ & Plantas \\
\hline $\begin{array}{l}\text { Índice de } \\
\text { Espacios } \\
\text { Libres }\end{array}$ & OSR & $\begin{array}{l}\text { El Open Space Ratio (OSR) es definido por la relación entre los } \\
\text { espacios libres y el área total construida en determinado sector } \\
\text { bajo análisis. Este indicador es considerado una medida de la } \\
\text { calidad del plano urbano, una vez que expresa el balance entre } \\
\text { el deseo de maximizar la superficie construida y las demandas } \\
\text { pública y privada por un espacio libre adecuado. }\end{array}$ & $\begin{aligned} \mathrm{OSR}= & (1-\mathrm{GSI}) / \mathrm{FSI} \\
& \circ \\
\mathrm{OSR}= & (\mathrm{A}-\mathrm{B}) / \mathrm{F}\end{aligned}$ & / \\
\hline $\begin{array}{l}\text { Densidad de } \\
\text { la red viaria }\end{array}$ & N & $\begin{array}{l}\text { Ratio entre la extensión de las vías de circulación (motorizada, } \\
\text { ciclística y peatonal) - Network (N) - y el área de la superficie } \\
\text { considerada. }\end{array}$ & $\mathrm{N}=\left(\sum \mathrm{li}+\sum \mathrm{le} / 2\right) / \mathrm{A}$ & $\mathrm{m} / \mathrm{m}^{2}$ \\
\hline $\begin{array}{l}\text { Ancho medio } \\
\text { de las vías }\end{array}$ & $b$ & $\begin{array}{l}\text { Ancho medio (breadth - b) entre las vías de circulación } \\
\text { consideradas para el cálculo de N. }\end{array}$ & $\begin{array}{c}b=2[1- \\
\left.\sqrt{ }\left(G S I_{+} / G S I_{m}\right)\right] / N\end{array}$ & m \\
\hline $\begin{array}{l}\text { Ancho de } \\
\text { malla }\end{array}$ & w & $\begin{array}{l}\text { Distancia media entre vías en el ámbito del tejido, ofrece la } \\
\text { distancia media que el peatón debe caminar entre dos esquinas. } \\
\text { Se puede afirmar que el ancho de malla mide la permeabilidad } \\
\text { del tejido urbano a vehículos y peatones. }\end{array}$ & $\begin{array}{c}\mathrm{w}=2 / \mathrm{N} \\
0 \\
\mathrm{w}=2 \mathrm{~A} /\left(\sum \mathrm{li}+\sum \mathrm{le} / 2\right)\end{array}$ & $\mathrm{m}$ \\
\hline \multicolumn{5}{|c|}{$\begin{array}{l}\text { F: área bruta edificada }\left(\mathrm{m}^{2}\right) \text {; } \\
\text { B: área total de las proyecciones de los edificios sobre el suelo }\left(\mathrm{m}^{2}\right) \text {; } \\
\text { A: área superficial del tejido urbano }\left(\mathrm{m}^{2}\right) \text {; } \\
\mathrm{I}_{\mathrm{i}} \text { : extensión de la red viaria interior al tejido urbano }(\mathrm{m}) \text {; } \\
\mathrm{l}_{\mathrm{e}} \text { : extensión de la red viaria exterior (colindante) al tejido urbano }(\mathrm{m}) \text {; } \\
\mathrm{GSI}_{+} \text {: Índice de Ocupación Bruta del tejido urbano; } \\
\mathrm{GSI}_{\mathrm{m}} \text { : Índice de Ocupación Bruta medio de las manzanas en el tejido }\end{array}$} \\
\hline
\end{tabular}

Fuente: elaboración propia con base en Pont \& Haupt (2009)

A partir de estas definiciones, se puede decir que determinado tejido urbano consiste en una combinación específica de, por un lado, un tipo de red viaria - definido por los indicadores $\mathrm{N}$ y b (caracterizadores del plano), con, por otro lado, el tipo edificatorio- definidos por los atributos FSI, GSI, OSR y L (caracterizadores de lo edificado) (Pont \& Haupt, 2009).

Además de los anteriores, otros indicadores fueron considerados, conforme se presenta en la Tabla 2. Los valores de superficie peatonal, superficies verdes, área media de las manzanas y 
longitud de la red viaria fueron conseguidos mediante análisis por geoprocesamiento sobre base fornecida por el Ayuntamiento de Madrid (2016).

Tabla 2. Indicadores morfológicos de los tejidos urbanos analizados

\begin{tabular}{|c|c|}
\hline \multicolumn{2}{|c|}{ INDICADORES MORFOLÓGICOS DE LOS TEJIDOS } \\
\hline Indicador & Sigla \\
\hline Superficie total del tejido $\left(\mathrm{m}^{2}\right)$ & A \\
\hline Superficie ocupada en planta por la edificación $\left(\mathrm{m}^{2}\right)$ & B \\
\hline Superficie de espacio libre total $\left(\mathrm{m}^{2}\right)$ & $A-B$ \\
\hline Proporción de superficie libre total (\%) & $\%(A-B)$ \\
\hline Superficie peatonal $\left(\mathrm{m}^{2}\right)$ & $A_{\text {peat }}$ \\
\hline Proporción de superficie peatonal (\%) & $\%\left(A_{\text {peat }}\right)$ \\
\hline Superficies verdes públicas $\left(\mathrm{m}^{2}\right)$ & $A_{\text {verde }}$ \\
\hline Proporción de superficies verdes públicas (\%) & $\%\left(A_{\text {verde }}\right)$ \\
\hline Superficie libre pública ${ }^{1}\left(\mathrm{~m}^{2}\right)$ & $A l_{p b}$ \\
\hline Proporción de superficie libre pública ${ }^{1}$ (\%) & $\%\left(A l_{p b}\right)$ \\
\hline Dimensión media de la manzana $\left(\mathrm{m}^{2}\right)$ & M \\
\hline Población ${ }^{2}$ & $P$ \\
\hline Densidad poblacional (P/Ha) & $\rho P$ \\
\hline Número de viviendas & V \\
\hline Densidad de viviendas $(\mathrm{V} / \mathrm{Ha})$ & $\rho V$ \\
\hline Índice de ocupación bruta (B/A) (Ground Space Index) & GSI \\
\hline Edificabilidad bruta (F/A) (Floor Space Index) & $\mathrm{FSI}$ \\
\hline Altura media de la edificación ( $n^{\circ}$ plantas) (Layers) & L \\
\hline Índice de Espacios Libres (A-B/F) (Open Space Rate) & OSR \\
\hline Densidad de la red viaria $\left(\mathrm{m} / \mathrm{m}^{2}\right)$ (Network) & $\mathrm{N}$ \\
\hline Ancho medio de vías (m) (Breadth) & $\mathrm{b}$ \\
\hline Ancho de malla (m) (Width) & w \\
\hline 1 Descontándose la superficie rodada. & \\
\hline $\begin{array}{l}2 \text { Estimación de acuerdo con el número medio de per } \\
\text { en el barrio, según Ayuntamiento de Madrid (2018a). }\end{array}$ & hogar \\
\hline
\end{tabular}

Fuente: elaboración propia

\subsection{La diversidad urbana}

Se procedió, igualmente, para cada tejido urbano, a la recogida de los valores correspondientes a los indicadores funcionales, que denotan por quién y cómo el suelo es apropiado. La Tabla 3 expone las informaciones tomadas en consideración. 
Tabla 3. Indicadores funcionales de los tejidos urbanos analizados

\begin{tabular}{|c|c|}
\hline \multicolumn{2}{|c|}{ INDICADORES FUNCIONALES DE LOS TEJIDOS } \\
\hline Indicador & Sigla \\
\hline Superficie de suelo residencial $\left(\mathrm{m}^{2}\right)$ & r \\
\hline $\begin{array}{l}\text { Superficie de suelo destinado a actividades económicas } \\
\text { (comercio, oficina, industria, ocio y hostelería) - }\left(\mathrm{m}^{2}\right)\end{array}$ & c \\
\hline Superficie de suelo destinado a equipamientos $\left(\mathrm{m}^{2}\right)$ & $\mathrm{e}$ \\
\hline Superficie total de usos $(r+c+d)\left(m^{2}\right)$ & $t$ \\
\hline Proporción de suelo destinado a residencias $(r / t) .100$ & $\%(r)$ \\
\hline $\begin{array}{l}\text { Proporción de suelo destinado a comercio, oficina, } \\
\text { industria, ocio y hostelería (c/t). } 100\end{array}$ & $\%(c)$ \\
\hline Proporción de suelo destinado a equipamientos $(\mathrm{e} / \mathrm{t}) .100$ & $\%(e)$ \\
\hline Índice de Diversidad Urbana (Shannon-Weiner) & IDU \\
\hline Densidad potencial de empleados (Emp/Ha) & pEmp \\
\hline Fecha media de construcción de los edificios & Fecha \\
\hline $\begin{array}{l}\text { Renta media anual del hogar ( } € \text { ) en el tejido (media de } \\
\text { secciones censales), según INE (2019) }\end{array}$ & $\epsilon_{\text {renta }}(t)$ \\
\hline Precio medio de la vivienda en el tejido $(€)$ & $\epsilon_{\text {viv }}(t)$ \\
\hline Coeficiente de variación de los precios de la vivienda & $C \vee \epsilon_{\text {viv }}$ \\
\hline Superficie media de la vivienda $\left(\mathrm{m}^{2}\right)$ & $A_{\text {viv }}$ \\
\hline Coste relativo de la vivienda (tejido) $\left(€ / \mathrm{m}^{2}\right)^{1}$ & $\epsilon_{\text {viv }} / \mathrm{m}^{2}(t)$ \\
\hline Número medio de habitaciones por vivienda en venta & $h_{\text {viv }}$ \\
\hline Número medio de plazas de garaje por vivienda en venta & $g_{\text {viv }}$ \\
\hline $\begin{array}{l}\text { Densidad de paradas o estaciones de transp. público } \\
\text { (unidades } / \mathrm{Ha} \text { ) }\end{array}$ & pTP \\
\hline № de líneas de transporte público & $L_{t p}$ \\
\hline Alcance de las líneas de transporte público $(\mathrm{km})$ & $A_{t p}$ \\
\hline $\begin{array}{l}\text { De acuerdo com levantamiento propio sobre viviendas er } \\
\text { tejido en abril de } 2020 \text {. }\end{array}$ & enta en el \\
\hline
\end{tabular}

Fuente: elaboración propia

Los usos asignados al suelo, conforme la Sede Electrónica del Catastro (Ministerio de Hacienda, 2019) fueron agrupados en tres tipos: residencial, actividades económicas y equipamientos (Tabla 4), en acorde con el método propuesto por Van den Hoek (2010) y adaptado al caso español por Solís Trapero et al. (2019). 
Tabla 4. Clasificación de usos del suelo

\begin{tabular}{|c|c|}
\hline Clasificación & $\begin{array}{c}\text { Usos según Sede } \\
\text { Electrónica del Catastro }\end{array}$ \\
\hline Residencial & Residencial \\
\hline \multirow{5}{*}{ Actividades económicas } & Comercial \\
\hline & Oficinas \\
\hline & Industrial \\
\hline & Ocio y hostelería \\
\hline & Edificio singular ${ }^{1}$ \\
\hline \multirow{6}{*}{ Equipamientos } & Deportivo \\
\hline & Espectáculos \\
\hline & Sanidad y Beneficencia \\
\hline & Cultural \\
\hline & Religioso \\
\hline & Edificio singular ${ }^{1}$ \\
\hline
\end{tabular}

Fuente: elaboración propia

Tras el cálculo de la proporción de suelo conferido a cada clase sobre el área total del tejido, se valoró la diversidad de usos del suelo, con base en el Índice de Diversidad Urbana (ShannonWeiner) - IDU, recomendado por Solís Trapero et al. (2019) y calculado conforme se presenta:

$$
\mathrm{IDU}=-\Sigma(\mathrm{Pi} \log 2 \mathrm{Pi})
$$

en que,

$\mathrm{Pi}$ = proporción de cada uso.

El valor de IDU mínimo, es decir, cero, indica monofuncionalidad, o sea, ocurren apenas un tipo de uso del suelo. El valor máximo posible es $\log 2 n$, en que $n$ es el número de clases consideradas. Como este estudio tiene en cuenta tres clases, la diversidad máxima de un tejido urbano sería 1,585 - situación teórica de distribución equitativa entre los usos y máxima heterogeneidad funcional.

El número de empleados en actividades económicas en el tejido fue estimado con base en sugerencia de Hernández Aja (1997), para quien, en el contexto de una gran ciudad española se presupone $25 \mathrm{~m}^{2}$ de superficie terciaria o $40 \mathrm{~m}^{2}$ de superficie industrial para cada empleado y su densidad ( $n^{\circ}$ potencial de empleados/hectárea) ofrece una idea del flujo de personas que se desplazan al tejido diariamente para trabajar.

Tanto los datos sobre renta media anual por hogar cuanto los referentes al precio relativo de la vivienda $\left(€ / \mathrm{m}^{2}\right)$ fueron obtenidos para para el tejido urbano estudiado. En este caso, la renta 
media por hogar fue calculada de forma aproximada con base en la media aritmética simple de los valores ofrecidos por el Instituto Nacional de Estadística para las secciones censales abarcadas en el tejido (INE, 2019). Los valores referentes al mercado y a las características de la vivienda en el espacio analizado fueron obtenidos por medio de búsqueda de productos en venta en abril de 2020 junto a dos corporaciones de intermediación inmobiliaria: Idealista (2020) y Fotocasa (2020). El área media de la vivienda en el tejido urbano, sin embargo, fue calculado con base en la totalidad de las residencias a través de la Sed Electrónica de Catastro (Ministerio de Hacienda, 2019).

El coeficiente de variación de los precios las viviendas en venta en el tejido urbano fue obtenido por constituirse en un indicador indirecto (proxy) de la mezcla social que puede existir en el respectivo espacio. Varía de cero a uno y cuanto más elevado su valor mayor la dispersión de los precios en torno a la media, indicando una oferta de inmuebles que puede atender a distintos rangos de compradores.

Por fin, se examinó la accesibilidad del tejido urbano y su conexión con el contexto metropolitano madrileño mediante tres indicadores: densidad de paradas o estaciones de transporte público, número de líneas y alcance de las mismas. Este último fue obtenido por la suma de las longitudes de todas las líneas que atienden al sector urbano considerado en los tres modales analizados (autobús, metro y cercanías) sin necesidad de transferencia. Estas informaciones fueron conseguidas junto a la Empresa Municipal de Transportes de Madrid (EMT Madrid, 2015) para la obtención de datos sobre el servicio de autobuses, al Metro Madrid (2019) para el servicio de metro y a la Red Nacional de los Ferrocarriles Españoles (2019) para el de Cercanías (trenes metropolitanos). Para la determinación de los servicios de transporte público se consideraron todas las paradas o estaciones y líneas que sirven el espacio interior al tejido, bien como hasta un radio de quinientos metros de sus límites, distancia considerada fácilmente accesible a pie.

Tras los análisis se elaboraron matrices de correlación para verificar la existencia de influencias entre los indicadores funcionales y entre morfológicos y funcionales, bien como el grado en que estas ocurren. Para tanto se utilizó el coeficiente de correlación:

$$
\operatorname{Correl}(X, Y)=\frac{\sum(x-\bar{x})(y-\bar{y})}{\sqrt{\sum(x-\bar{x})^{2} \sum(y-\bar{y})^{2}}}
$$


en que,

$x=$ valor del primer indicador en la correlación para determinado tejido;

$y=$ valor del segundo indicador correlacionado para determinado tejido;

$\bar{x}=$ media de los valores del indicador $\mathrm{x}$ para los quince tejidos;

$\bar{y}=$ media de los valores del indicador y para los quince tejidos.

\section{Resultados}

La Figura 1 localiza los tejidos urbanos investigados, en cuanto las Tablas 5 y 6 presentan los valores correspondientes a los indicadores morfológicos y funcionales, respectivamente. Para la identificación de los tejidos, este trabajo utiliza siglas compuestas por letras y números, las primeras correspondiendo a la inicial de la denominación de la clase morfológica y los segundos al estándar socioeconómico (1, superior; 2, mediano; 3, inferior).

Figura 1. Localización de los tejidos urbanos investigados (C: casco histórico;

$\mathrm{E}$ : ensanches; V: viviendas unifamiliares; B: bloques exentos; $\mathrm{N}$ : nuevos ensanches)
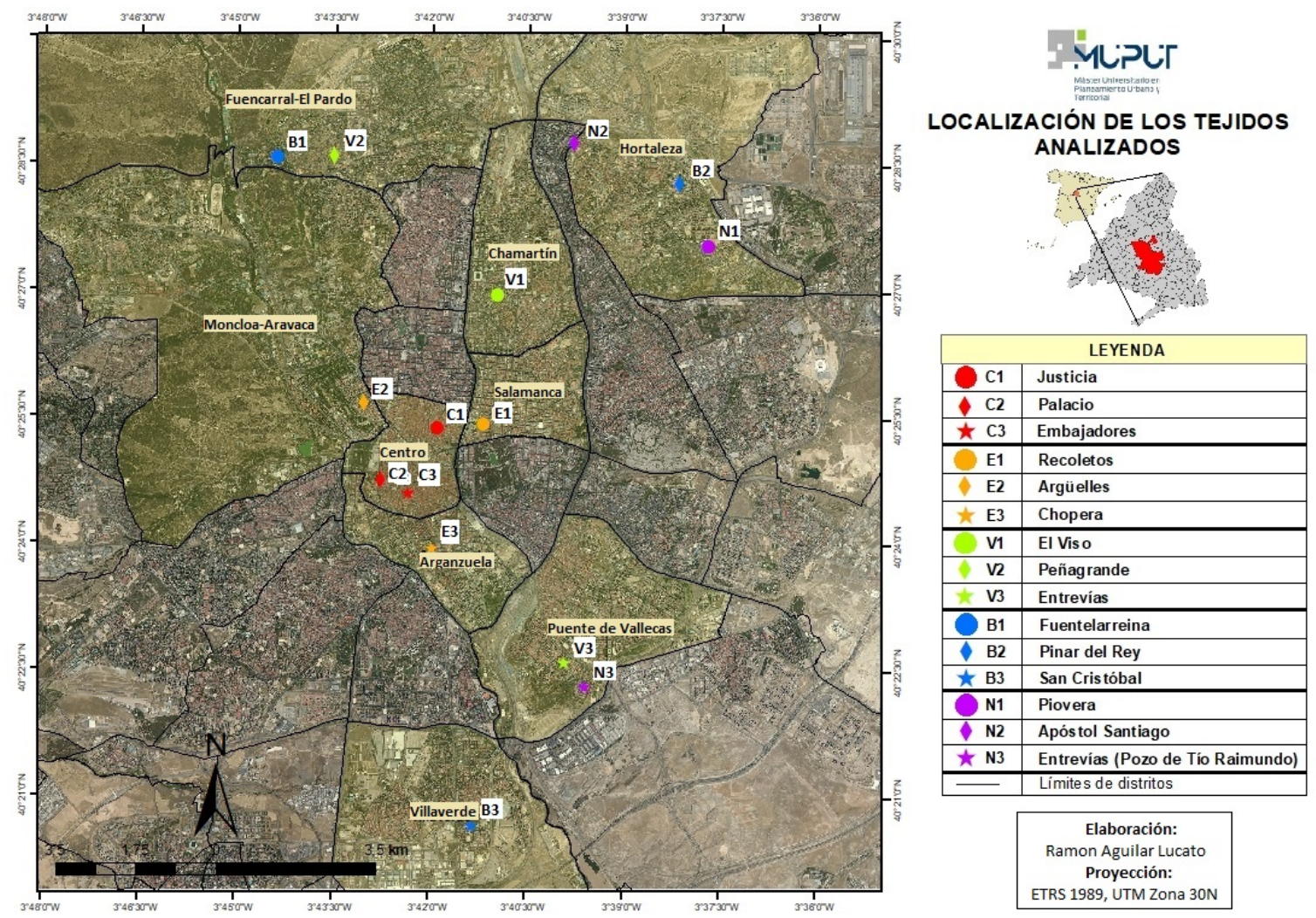

Fuente: elaboración propia 
Tabla 5. Indicadores morfológicos de los quince tejidos estudiados.

Siglas explicadas en la Tabla 2

\begin{tabular}{|c|c|c|c|c|c|}
\hline Tejido Indicador & $\begin{array}{c}\text { C1 } \\
\text { Justicia }\end{array}$ & $\begin{array}{c}\text { C2 } \\
\text { Palacio }\end{array}$ & $\begin{array}{c}\text { C3 } \\
\text { Embajadores }\end{array}$ & $\begin{array}{c}\text { E1 } \\
\text { Recoletos }\end{array}$ & $\begin{array}{c}\text { E2 } \\
\text { Argüelles }\end{array}$ \\
\hline$A\left(m^{2}\right)$ & 47485,70 & 44573,75 & 51500,05 & 102787,00 & 54354,58 \\
\hline$B\left(m^{2}\right)$ & 34351,00 & 25306,00 & 36543,00 & 59708,00 & 33111,00 \\
\hline$A-B\left(m^{2}\right)$ & 13134,70 & 19267,75 & 14957,05 & 43079,00 & 21243,58 \\
\hline$\%(A-B)$ & 27,66 & 43,23 & 29,04 & 41,91 & 39,08 \\
\hline$A_{\text {peat }}\left(m^{2}\right)$ & 5452,80 & 7323,94 & 5239,19 & 15517,45 & 5739,81 \\
\hline$\%\left(A_{\text {peat }}\right)$ & 11,48 & 16,43 & 10,17 & 15,10 & 10,56 \\
\hline$A_{\text {verde }}\left(m^{2}\right)$ & 0 & 1151,19 & 8,97 & 122,78 & 0 \\
\hline$\%\left(\mathrm{~A}_{\text {verde }}\right)$ & 0 & 2,58 & 0,02 & 0,12 & 0 \\
\hline$A l_{p b}$ & 5452,80 & 8475,13 & 5248,16 & 15640,23 & 5739,81 \\
\hline$\%\left(A I_{p b}\right)$ & 11,48 & 19,01 & 10,19 & 15,22 & 10,56 \\
\hline$M\left(m^{2}\right)$ & 5344,71 & 2354,00 & 5932,29 & 10343,08 & 6627,50 \\
\hline$P$ & 3191 & 2.178 & 3.535 & 2527 & 3114 \\
\hline$\rho P(P / H a)$ & 671,99 & 488,63 & 686,41 & 245,85 & 572,90 \\
\hline V & 1620 & 1089 & 1. 33 & 1080 & 1348 \\
\hline$\rho V(V / H a)$ & 341,16 & 244,31 & 336,50 & 105,46 & 248,00 \\
\hline GSI (B/A) & 0,72 & 0,57 & 0,71 & 0,58 & 0,61 \\
\hline $\mathrm{FSI}(\mathrm{F} / \mathrm{A})$ & 3,71 & 3,04 & 3,23 & 3,83 & 4,27 \\
\hline L (plantas) & 5,15 & 5,35 & 4,56 & 6,60 & 7,01 \\
\hline OSR & 0,08 & 0,14 & 0,09 & 0,11 & 0,09 \\
\hline $\mathrm{N}\left(\mathrm{m} / \mathrm{m}^{2}\right)$ & 0,0264 & 0,0394 & 0,0262 & 0,0184 & 0,0213 \\
\hline$b(m)$ & 8,74 & 10,36 & 7,77 & 17,28 & 13,40 \\
\hline$w(m)$ & 75,76 & 50,76 & 76,34 & 108,70 & 93,90 \\
\hline Tejido Indicador & $\begin{array}{c}\text { E3 } \\
\text { Chopera }\end{array}$ & $\begin{array}{c}\text { VT } \\
\text { El Viso }\end{array}$ & $\begin{array}{c}\text { V2 } \\
\text { Peñagrande }\end{array}$ & $\begin{array}{c}\text { V3 } \\
\text { Entrevías }\end{array}$ & $\begin{array}{c}\text { B1 } \\
\text { Fuentelarreina }\end{array}$ \\
\hline$A\left(m^{2}\right)$ & 55392,51 & 85471,67 & 60084,18 & 55740,60 & 92801,98 \\
\hline$B\left(m^{2}\right)$ & 30231,00 & 22164,00 & 16839,00 & 23405,00 & 17236,00 \\
\hline$A-B\left(m^{2}\right)$ & 25161,51 & 63307,67 & 43245,18 & 32335,60 & 75565,98 \\
\hline$\%(A-B)$ & 45,42 & 74,07 & 71,97 & 58,01 & 81,43 \\
\hline$A_{\text {peat }}\left(\mathrm{m}^{2}\right)$ & 8900,00 & 8607,97 & 3811,89 & 7802,16 & 6453,40 \\
\hline$\%\left(A_{\text {peat }}\right)$ & 16,07 & 10,07 & 6,34 & 14,00 & 6,95 \\
\hline$A_{\text {verde }}\left(m^{2}\right)$ & 216,84 & 0 & 0 & 2994,72 & 1547,74 \\
\hline$\%\left(\mathrm{~A}_{\text {verde }}\right)$ & 0,39 & 0 & 0 & 5,37 & 1,67 \\
\hline$A I_{p b}$ & 9116,84 & 8607,97 & 3811,89 & 10796,88 & 8001,14 \\
\hline$\%\left(A I_{p b}\right)$ & 16,46 & 10,07 & 6,34 & 19,37 & 8,62 \\
\hline$M\left(m^{2}\right)$ & 6915,49 & 4702,31 & 5426,78 & 5393,29 & 19101,25 \\
\hline $\mathrm{P}$ & 4.316 & 643 & 363 & 1627 & 1.385 \\
\hline$\rho P(P / H a)$ & 779,17 & 75,23 & 59,66 & 291,89 & 149,24 \\
\hline V & 1854 & 228 & 138 & 605 & 474 \\
\hline$\rho \vee(V / H a)$ & 334,70 & 26,68 & 22,97 & 108,54 & 51,08 \\
\hline GSI (B/A) & 0,55 & 0,26 & 0,28 & 0,42 & 0,19 \\
\hline $\mathrm{FSI}(\mathrm{F} / \mathrm{A})$ & 4,33 & 0,94 & 0,73 & 0,80 & 1,33 \\
\hline
\end{tabular}


Tabla 5. Continuación

\begin{tabular}{|c|c|c|c|c|c|}
\hline Tejido $\quad$ Indicador & $\begin{array}{c}\text { E3 } \\
\text { Chopera }\end{array}$ & $\begin{array}{c}\text { V7 } \\
\text { El Viso } \\
\end{array}$ & $\begin{array}{c}\text { V/2 } \\
\text { Peñagrande } \\
\end{array}$ & $\begin{array}{c}\text { V/3 } \\
\text { Entrevías } \\
\end{array}$ & $\begin{array}{c}B 1 \\
\text { Fuentelarreina }\end{array}$ \\
\hline L (plantas) & 7,94 & 3,62 & 2,62 & 1,90 & 7,14 \\
\hline OSR & 0,10 & 0,79 & 0,98 & 0,73 & 0,61 \\
\hline $\mathrm{N}\left(\mathrm{m} / \mathrm{m}^{2}\right)$ & 0,0224 & 0,0249 & 0,0240 & 0,0456 & 0,0139 \\
\hline$b(m)$ & 18,21 & 12,06 & 7,71 & 7,76 & 13,11 \\
\hline$w(m)$ & 89,29 & 80,42 & 83,33 & 43,86 & 143,88 \\
\hline Tejido Indicador & $\begin{array}{c}\text { B2 } \\
\text { Pinar del Rey }\end{array}$ & $\begin{array}{c}\text { B3 } \\
\text { San Cristóbal }\end{array}$ & $\begin{array}{c}\text { N1 } \\
\text { Piovera }\end{array}$ & $\begin{array}{c}\text { N2 } \\
\text { Ap. Santiago }\end{array}$ & $\begin{array}{c}\text { N3 } \\
\text { Entrevías (Pozo } \\
\text { T. Raimundo) }\end{array}$ \\
\hline$A\left(m^{2}\right)$ & 76400,68 & 52659,21 & 91341,24 & 62589,62 & 48368,71 \\
\hline$B\left(m^{2}\right)$ & 18242,00 & 11739,00 & 26651,00 & 13877,00 & 13417,00 \\
\hline A-B $\left(m^{2}\right)$ & 58 158,68 & 40920,21 & 64690,24 & 48712,62 & 34951,71 \\
\hline$\%(A-B)$ & 76,12 & 77,71 & 70,82 & 77,83 & 72,26 \\
\hline$A_{\text {peat }}\left(m^{2}\right)$ & 9654,82 & 22040,97 & 9402,15 & 7158,49 & 22228,62 \\
\hline$\%\left(A_{\text {peat }}\right)$ & 12,64 & 41,86 & 10,29 & 11,44 & 45,96 \\
\hline$A_{\text {verde }}\left(m^{2}\right)$ & 19428,60 & 6847,01 & 4881,03 & 1102,69 & 2172,73 \\
\hline$\%\left(\mathrm{~A}_{\text {verde }}\right)$ & 25,43 & 13,00 & 5,34 & 1,76 & 4,49 \\
\hline$A I_{p b}$ & 29083,42 & 28887,98 & 14283,18 & 8261,18 & 24401,35 \\
\hline$\%\left(A I_{p b}\right)$ & 38,07 & 54,86 & 15,64 & 13,20 & 50,45 \\
\hline$M\left(m^{2}\right)$ & 29165,50 & 14289,50 & 13873,20 & 10377,25 & 15660,00 \\
\hline$P$ & 3006 & 3109 & 2748 & 2.006 & 1.412 \\
\hline$\rho P(P / H a)$ & 393,45 & 590,40 & 300,85 & 320,50 & 291,92 \\
\hline V & 1217 & 1.016 & 904 & 757 & 525 \\
\hline$\rho \vee(V / H a)$ & 159,29 & 192,94 & 98,97 & 120,95 & 108,54 \\
\hline GSI (B/A) & 0,24 & 0,22 & 0,29 & 0,22 & 0,28 \\
\hline $\mathrm{FSI}(\mathrm{F} / \mathrm{A})$ & 1,51 & 1,33 & 1,67 & 1,73 & 1,17 \\
\hline L (plantas) & 6,30 & 5,97 & 5,72 & 7,78 & 4,23 \\
\hline OSR & 0,51 & 0,58 & 0,42 & 0,45 & 0,62 \\
\hline$N\left(\mathrm{~m} / \mathrm{m}^{2}\right)$ & 0,0371 & 0,0515 & 0,0196 & 0,0174 & 0,0439 \\
\hline$b(m)$ & 6,48 & 10,39 & 12,90 & 21,09 & 8,80 \\
\hline$w(m)$ & 53,91 & 38,83 & 102,04 & 114,94 & 45,56 \\
\hline
\end{tabular}

Fuente: elaboración propia 
Tabla 6. Indicadores funcionales de los quince tejidos estudiados.

Siglas explicadas en la Tabla 3

\begin{tabular}{|c|c|c|c|c|c|}
\hline Tejido Indicador & $\begin{array}{c}\text { C1 } \\
\text { Justicia }\end{array}$ & $\begin{array}{c}\text { C2 } \\
\text { Palacio }\end{array}$ & $\begin{array}{c}\text { C3 } \\
\text { Embajadores }\end{array}$ & $\begin{array}{c}E 1 \\
\text { Recoletos }\end{array}$ & $\begin{array}{c}E 2 \\
\text { Argüelles }\end{array}$ \\
\hline$r\left(m^{2}\right)$ & 114957,00 & 81893,00 & 109198,00 & 179114,00 & 143668,00 \\
\hline$c\left(m^{2}\right)$ & 30214 & 17042,00 & 27658,00 & 111020,00 & 24429,00 \\
\hline e $\left(m^{2}\right)$ & 0 & 13064,00 & 2323,00 & 20667,00 & 13185,00 \\
\hline$t\left(m^{2}\right)$ & 145171,00 & 111999,00 & 139179,00 & 310801,00 & 181282,00 \\
\hline$\%(r)$ & 79,19 & 73,12 & 78,46 & 57,63 & 79,25 \\
\hline$\%(c)$ & 20,81 & 15,22 & 19,87 & 35,72 & 13,48 \\
\hline$\%(e)$ & 0 & 11,66 & 1,67 & 6,65 & 7,27 \\
\hline $\mathrm{IDU}^{1}$ & 0,7379 & 1,1052 & 0,8364 & 1,2487 & 0,9305 \\
\hline pEmp (Emp/Ha) & 254,60 & 270,11 & 236,70 & 514,17 & 267,87 \\
\hline Fecha $^{2}$ & 1915 & 1909 & 1914 & 1925 & 1946 \\
\hline$€_{\text {renta }}(t)^{3}$ & 31070,00 & 33178,00 & 24769,00 & 89015,00 & 48955,00 \\
\hline$\epsilon_{\text {viv }}(t)^{5}$ & 662813,00 & $683.824,00$ & 377076,00 & 2350200,00 & 881400,00 \\
\hline$C \vee \epsilon_{\text {viv }}$ & 0,65 & 0,86 & 0,56 & 0,48 & 0,49 \\
\hline$A_{\text {viv }}\left(m^{2}\right)$ & 70,96 & 75,20 & 63,01 & 165,85 & 106,98 \\
\hline$€_{\text {viv }} / \mathrm{m}^{2}(\mathrm{t})$ & 6024,50 & 5019,74 & 4125,90 & 9295,07 & 5048,02 \\
\hline$h_{\text {viv }}$ & 2,18 & 2,06 & 2,12 & 4,07 & 3,65 \\
\hline$g_{\text {viv }}$ & 0,05 & 0,12 & 0,03 & 0,36 & 0,30 \\
\hline pTP (unidades/Ha) & 0,4669 & 0,3330 & 0,4044 & 0,3141 & 0,2692 \\
\hline$L_{t p}$ & 52 & 18 & 29 & 42 & 29 \\
\hline$A_{t p}(k m)$ & 535,20 & 174,80 & 307,80 & 422,40 & 406,80 \\
\hline Tejido Indicador & $\begin{array}{c}\text { E3 } \\
\text { Chopera }\end{array}$ & $\begin{array}{c}\text { V7 } \\
\text { El Viso }\end{array}$ & $\begin{array}{c}\text { V2 } \\
\text { Peñagrande }\end{array}$ & $\begin{array}{c}\text { V3 } \\
\text { Entrevías }\end{array}$ & $\begin{array}{c}\text { B1 } \\
\text { Fuentelarreina }\end{array}$ \\
\hline$r\left(m^{2}\right)$ & 150194,00 & 61909,00 & 31790,00 & 40104,00 & 78181,00 \\
\hline$c\left(m^{2}\right)$ & 26501,00 & 6074,00 & 0 & 2004,00 & 1939,00 \\
\hline $\mathrm{e}\left(\mathrm{m}^{2}\right)$ & 1642,00 & 4091,00 & 2575,00 & 382,00 & 196,00 \\
\hline$t\left(m^{2}\right)$ & 178337,00 & 72074,00 & 34365,00 & 42490,00 & 80316,00 \\
\hline$\%(r)$ & 84,22 & 85,90 & 92,51 & 94,38 & 97,34 \\
\hline$\%(c)$ & 14,86 & 8,43 & 0 & 4,72 & 2,41 \\
\hline$\%(e)$ & 0,92 & 5,68 & 7,49 & 0,90 & 0,24 \\
\hline IDU 1 & 0,6796 & 0,7242 & 0,3839 & 0,3478 & 0,1883 \\
\hline$\rho \operatorname{Emp}(\mathrm{Emp} / \mathrm{Ha})$ & 203,28 & 47,27 & 16,31 & 17,04 & 8,41 \\
\hline Fecha $^{2}$ & 1960 & 1966 & 1979 & 1959 & 1975 \\
\hline$€_{\text {renta }}\left(\right.$ tejido) ${ }^{3}$ & 36957,00 & $103573,08^{4}$ & 46889,00 & 22397,50 & 84172,50 \\
\hline$€_{\mathrm{viv}}{ }^{5}$ & 349279,00 & 2207083,00 & 839643,00 & 130800,00 & 840333,00 \\
\hline$C \vee \epsilon_{\text {viv }}$ & 0,32 & 0,67 & 0,31 & 0,17 & 0,25 \\
\hline$A_{\text {viv }}\left(m^{2}\right)$ & 81,01 & 271,53 & 230,36 & 66,29 & 164,94 \\
\hline$€_{\text {viv }} / \mathrm{m}^{2}(\mathrm{t})$ & 3477,61 & 6929,54 & 3422,84 & 1749,73 & 4234,84 \\
\hline$h_{\text {viv }}$ & 2,71 & 4,54 & 4,86 & 2,40 & 3,87 \\
\hline$g_{\text {viv }}$ & 0,21 & 1,08 & 1,71 & 0,60 & 1,40 \\
\hline pTP (unidades/Ha) & 0,3532 & 0,3818 & 0,3091 & 0,3702 & 0,1493 \\
\hline$L_{t p}$ & 25 & 22 & 13 & 14 & 4 \\
\hline$A_{t p}(k m)$ & 317,60 & 241,80 & 135,90 & 234,50 & 37,50 \\
\hline
\end{tabular}


Tabla 6. Continuación

\begin{tabular}{|c|c|c|c|c|c|}
\hline Tejido Indicador & $\begin{array}{l}\text { B2 } \\
\text { Pinar del Rey }\end{array}$ & $\begin{array}{l}\text { B3 } \\
\text { San Cristóbal }\end{array}$ & $\begin{array}{l}\text { N1 } \\
\text { Piovera }\end{array}$ & $\begin{array}{l}\text { N2 } \\
\text { Ap. Santiago }\end{array}$ & $\begin{array}{l}\text { N3 } \\
\text { Entrevías (Pozo } \\
\text { T. Raimundo) }\end{array}$ \\
\hline$r\left(m^{2}\right)$ & 90988,00 & 61308,00 & 81238,00 & 64302,00 & 46557,00 \\
\hline$c\left(m^{2}\right)$ & $4.561,00$ & 1406,00 & 7685,00 & 4320,00 & 3552,00 \\
\hline e $\left(m^{2}\right)$ & 295 & 0 & 0 & 0 & 1835,00 \\
\hline$\dagger\left(m^{2}\right)$ & 95844,00 & 62714,00 & 88923,00 & 68622,00 & 51944,00 \\
\hline$\%(r)$ & 94,93 & 97,76 & 91,36 & 93,70 & 89,63 \\
\hline$\%(c)$ & 4,76 & 2,24 & 8,64 & 6,30 & 6,84 \\
\hline$\%(\mathrm{e})$ & 0,31 & 0 & 0 & 0 & 3,53 \\
\hline IDU 1 & 0,3062 & 0,1548 & 0,4243 & 0,3393 & 0,5765 \\
\hline$\rho \operatorname{emp}(\mathrm{Emp} / \mathrm{Ha})$ & 20,00 & 10,63 & 33,61 & 27,64 & 29,36 \\
\hline Fecha $^{2}$ & 1976 & 1965 & 1998 & 1999 & 1986 \\
\hline$€_{\text {renta }}\left(\right.$ tejido) ${ }^{3}$ & 32375,50 & 18926,00 & $97253,64^{4}$ & 33425,50 & 21601,00 \\
\hline$€_{\text {viv }}^{5}$ & 228825,00 & 88219,00 & 670000,00 & 391818,00 & 148377,00 \\
\hline$C \vee €_{\text {viv }}$ & 0,27 & 0,22 & 0,31 & 0,33 & 0,32 \\
\hline$A_{\text {viv }}\left(m^{2}\right)$ & 74,76 & 60,34 & 89,87 & 84,94 & 88,68 \\
\hline$\epsilon_{\text {viv }} / \mathrm{m}^{2}(\mathrm{t})$ & 2798,90 & 1379,09 & 5123,49 & 3652,47 & 1290,25 \\
\hline$h_{\text {viv }}$ & 2,58 & 2,89 & 2,53 & 3,00 & 3,42 \\
\hline$g_{\text {viv }}$ & 0,17 & 0 & 1,20 & 0,64 & 0 \\
\hline pTP (unidades/Ha) & 0,3009 & 0,0910 & 0,1744 & 0,2917 & 0,1878 \\
\hline$L_{t p}$ & 16 & 5 & 8 & 13 & 10 \\
\hline$A_{t p}(k m)$ & 146,50 & 144,30 & 72,60 & 215,80 & 211,40 \\
\hline \multicolumn{6}{|c|}{$\begin{array}{l}1 \text { El valor máximo para IDU (mayor diversidad posible) es } \log _{2}{ }^{n} \text {. Como n, para todos los tejidos considerados, es } 3 \text {, la } \\
\text { diversidad de usos absoluta sería 1,585, mientras } 0 \text { indicaría completa homogeneidad. }\end{array}$} \\
\hline \multicolumn{6}{|c|}{$\begin{array}{l}2 \text { Salvo excepciones, en la Sede Electrónica del Catastro, los edificios erigidos antes de } 1900 \text { son presentados con esta } \\
\text { fecha de construcción, hecho que sesga los valores para el casco histórico y para algunos barrios más antiguos del } \\
\text { ensanche tradicional. }\end{array}$} \\
\hline \multicolumn{6}{|l|}{${ }^{3}$ INE (2019). } \\
\hline \multicolumn{6}{|c|}{$\begin{array}{l}{ }^{4} \text { Dato exacto no disponible por exceder la cota superior divulgable. Se repite la información divulgada por Madrid } \\
\text { (2018b) para el barrio correspondiente. }\end{array}$} \\
\hline
\end{tabular}

Fuente: elaboración propia

A continuación, se procederá a la consideración de algunas características funcionales estudiadas en los quince tejidos y que contribuyen a la determinación de la estructura y de la dinámica urbanas de Madrid, a saber, renta media anual de hogar, precios medio y relativo de la vivienda, coeficiente de variación de precios de la vivienda (diversidad social), accesibilidad (alcance de las líneas de transporte público) y usos del suelo y diversidad urbana. En seguida, se presentarán las correlaciones observadas entre los indicadores funcionales y entre estos y los morfológicos. Conviene relatar que apenas las correlaciones moderadas, altas y muy altas -valor superior a $\pm 0,5$, de acuerdo con Amat Rodrigo (2016) - serán abordadas. Una discusión analítica de estos hallazgos se desarrollará en el apartado 4. 


\subsection{Análisis de indicadores funcionales}

La tabla 7 demuestra que el casco histórico posee tanto la menor amplitud de variación en la renta media anual por hogar (apenas del 34\%) cuanto el menor valor medio. Le siguen al casco como tejidos menos abonados, y con una diferencia creciente entre la menor y la mayor renta, los bloques exentos, los nuevos ensanches y las viviendas unifamiliares. En este caso, la amplitud es máxima, pues El Viso (V1) -el tejido con renta media superior entre todos los estudiadossupone ingresos un 362 \% más elevados que Entrevías (V3). Los ensanches tradicionales, a su vez, presumen la renta media más elevada, con el tejido E3 (Chopera) exponiendo ingresos medios superiores a los del tejido más acomodado del casco (C2, Palacio), además de la segunda menor amplitud entre los extremos (141\%).

\section{Tabla 7. Renta media anual del hogar por clase morfológica y nivel socioeconómico del tejido}

\begin{tabular}{|l|c|c|c|c|}
\hline Clase morf. & $\begin{array}{c}\text { Superior } \\
(1)\end{array}$ & $\begin{array}{c}\text { Intermediario } \\
(2)\end{array}$ & $\begin{array}{c}\text { Inferior } \\
(3)\end{array}$ & $\begin{array}{c}\text { Media clase } \\
\text { morf. }\end{array}$ \\
\hline Casco (C) & 31070,00 & 33178,00 & 24769,00 & 29662,33 \\
\hline Ensanches (E) & 89015,00 & 48955,00 & 36957,00 & 58309,00 \\
\hline Viv. unif. (V) & 103573,08 & 46889,00 & 22397,50 & 57619,86 \\
\hline Bloques exentos (B) & 84172,50 & 32375,50 & 18926,00 & 45158,00 \\
\hline Nuevos ensanches (N) & 97253,64 & 33425,50 & 21601,00 & 50760,05 \\
\hline Media nivel soc. & 81016,84 & 38964,60 & 24930,10 & 48303,85 \\
\hline
\end{tabular}

Fuente: elaboración propia

En lo que se refiere a los precios medio y relativo de la vivienda, conforme expone la tabla 8, los menores corresponden a la clase de bloques exentos, seguidos por los nuevos ensanches, el casco antiguo y las viviendas unifamiliares. En esta clase se encuentra la más pronunciada desigualdad de precios entre los tejidos de rango socioeconómico superior e inferior: una diferencia del $1587 \%$ entre los precios medios de V1 (El Viso) y V3 (Entrevías) y del $296 \%$ entre sus precios relativos (en este caso coincidente con la desigualdad entre los casos extremos de los nuevos ensanches). Por fin, los ensanches tradicionales, en compás con una renta media del hogar superior, dispone de los más elevados precios residenciales absolutos y relativos. 
Tabla 8. Precios medio $(€)$ y relativo $\left(€ / \mathrm{m}^{2}\right)$ de la vivienda en abril de 2020 por clase morfológica y nivel socioeconómico del tejido

\begin{tabular}{|l|c|c|c|c|}
\hline \multicolumn{5}{|c|}{ PRECIO MEDIO DE LA VIVIENDA POR CLASE MORFOLÓGICA Y NIVEL } \\
SOCIOECONÓMICO DEL TEJIDO ( $)$
\end{tabular}

Fuente: elaboración propia

En cuanto al coeficiente de variación del precio de la vivienda (proxy de la diversidad social en el tejido), se patentiza que los tejidos más centrales, especialmente del casco histórico, poseen la mayor diversidad de precios y, por inferencia, la más elevada mezcla social. Ese suceso, combinado a precios medios absolutos moderados de la vivienda (entre 377 y 663 mil euros), hace con que efectivamente los barrios centrales se constituyan en entornos diversos no apenas en lo que refiere a los visitantes que circulan por ellos cotidianamente y a las funciones que albergan (Tabla 9).

Tabla 9. Coeficiente de variación del precio de la vivienda por clase morfológica y nivel socioeconómico del tejido

\begin{tabular}{|l|c|c|c|c|}
\hline Clase morf. & $\begin{array}{c}\text { Superior soc. } \\
(1)\end{array}$ & $\begin{array}{c}\text { Intermediario } \\
(2)\end{array}$ & $\begin{array}{c}\text { Inferior } \\
(3)\end{array}$ & $\begin{array}{c}\text { Media clase } \\
\text { morf. }\end{array}$ \\
\hline Casco (C) & 0,65 & 0,86 & 0,56 & 0,69 \\
\hline Ensanches (E) & 0,48 & 0,49 & 0,32 & 0,43 \\
\hline Viv. unif. (V) & 0,67 & 0,31 & 0,17 & 0,38 \\
\hline Bloques exentos (B) & 0,25 & 0,27 & 0,22 & 0,25 \\
\hline Nuevos ensanches (N) & 0,31 & 0,33 & 0,32 & 0,32 \\
\hline Media nivel soc. & 0,47 & 0,45 & 0,32 & 0,41 \\
\hline
\end{tabular}

Fuente: elaboración propia 
Los ensanches históricos son la segunda clase más diversa socioeconómicamente, heredando algo de la mezcla que los marcaba en sus primordios (Brandis, 1983), en cuanto la clase de viviendas unifamiliares surge en tercer lugar. En esta morfología ocurren los extremos de diversidad social: el tejido V1 (El Viso) aparece en segundo lugar entre los quince, pese a que el elevado precio medio de sus viviendas (2 $207083 €$, conforme Tabla 6) transforme las residencias menos caras en impeditivas a gran parte de la demanda; el tejido V3 (Entrevías), en el extremo opuesto, es el más homogéneo (y segregado), dadas las características socioeconómicas de su población. Los nuevos ensanches, por su turno, demuestran una baja diversidad social, así como valores semejantes en los tres tejidos analizados. Los bloques exentos, por fin, se revelan como los más exclusivos, por la modesta mezcla social que sus coeficientes de variación hacen suponer. Por eso, Fuentelarreina (B1), por el elevado precio medio de la vivienda (840 333,00 €), se presenta como un tejido fuertemente autosegregado, mientras San Cristóbal (B1), con los menores precios entre todos los estudiados (88 $219 €$ ), es un vecindario altamente segregado. El comportamiento del coeficiente de variación del precio de la vivienda -o de la diversidad social - en relación al contenido socioeconómico del entorno demuestra que los tejidos intermediarios son los más mezclados, pese a que el valor atípicamente elevado de El Viso (V1) haga con que el promedio del coeficiente de los tejidos del grupo 1 superen ligeramente al grupo 2.

En términos de accesibilidad, aquí analizada con base en el alcance total de las líneas de transporte público que sirven al sector urbano considerado, los tejidos centrales del casco y, principalmente, de los ensanches demuestran una ligación más amplia con el conjunto del área metropolitana madrileña (Tabla 10). En el primer caso, las desigualdades entre los tres tejidos son desmedidas, pues, mientras Justicia (C1) se ubica en el sector de Madrid mejor irrigado por el sistema de movilidad pública, cerca de la articulación entre los dos grandes ejes norte-sur del Paseo de la Castellana/Recoletos/Prado y este-oeste de la Calle de Alcalá/Gran Vía, Palacio (C2) se encuentra en una situación excéntrica en el contexto del casco, al margen de los principales recorridos de autobús, con poca accesibilidad al metro (apenas una estación y una línea en su proximidad) y sin conexión con el servicio de Cercanías. 
Tabla 10. Alcance total $(\mathrm{km})$, sin necesidad de transbordo, de las líneas de transporte público que sirven al entorno del tejido por clase morfológica

y nivel socioeconómico del tejido

\begin{tabular}{|l|c|c|c|c|}
\hline Clase morf. & $\begin{array}{c}\text { Superior } \\
(1)\end{array}$ & $\begin{array}{c}\text { Intermediario } \\
(2)\end{array}$ & $\begin{array}{c}\text { Inferior } \\
(3)\end{array}$ & $\begin{array}{c}\text { Media clase } \\
\text { morf. }\end{array}$ \\
\hline Casco (C) & 535,20 & 174,80 & 307,80 & 339,27 \\
\hline Ensanches (E) & 422,40 & 406,80 & 317,60 & 382,27 \\
\hline Viv. unif. (V) & 241,80 & 135,90 & 234,50 & 204,07 \\
\hline Bloques exentos (B) & 37,50 & 146,50 & 144,30 & 109,43 \\
\hline Nuevos ensanches (N) & 72,60 & 215,80 & 211,40 & 166,60 \\
\hline Media nivel soc. & 261,90 & 215,96 & 243,12 & 240,33 \\
\hline
\end{tabular}

Fuente: elaboración propia

Siguen los ensanches y el casco, en lo que se refiere al alcance de las líneas de transporte, los tejidos de viviendas unifamiliares, con destaque para El Viso (V1) -en el límite del sector más elegante de los ensanches y cerca del eje de la Castellana- y Entrevías (V3) con una relativamente pobre conexión por autobús y ausencia de metro compensadas por su estación de Cercanías, que, con tres líneas, le garantiza acceso directo a los principales centros del área metropolitana. En seguida se hallan los nuevos ensanches -en los que Piovera (N1) se destaca por su baja accesibilidad por modales públicos de transporte, siendo el segundo tejido más dependiente del automóvil, y los menos accesibles, los bloques exentos, con destaque para el casi desconectado tejido de Fuentelarreina (B1) que es servido apenas por cuatro líneas de autobús-.

A la postre, en lo que ciñe a los usos del suelo y al Índice de Diversidad Urbana (IDU), el rasgo más evidente es la mayor diversificación de usos en los tejidos más centrales, es decir, del casco y de los ensanches tradicionales. La Figura 2 representa el diagrama de mezcla de usos del suelo en los tejidos urbanos estudiados, de acuerdo con las tres clases consideradas en este trabajo: residencial, actividades económicas y equipamientos (conforme tabla 4), con base en las propuestas metodológicas de Van den Hoek (2010) y Solís Trapero et al. (2019). La Tabla 11, por su turno, expone el Índice de Diversidad Urbana por clase morfológica y nivel socioeconómico del tejido. 
Figura 2. Diagrama de mezcla de usos de los quince tejidos analizados

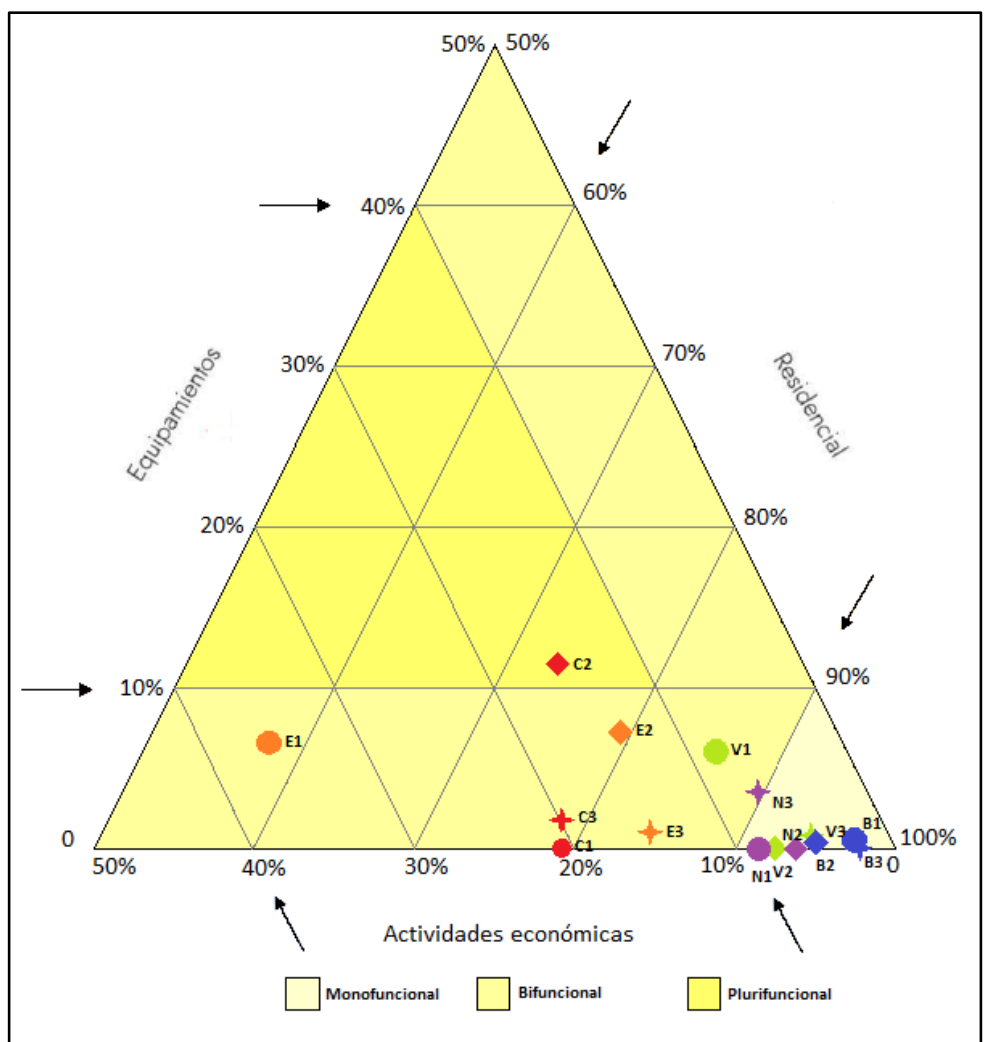

\begin{tabular}{|c|c|c|}
\hline \multicolumn{3}{|r|}{ LEYENDA } \\
\hline \multirow{3}{*}{ 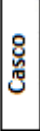 } & $\mathrm{C} 1$ & Justicia \\
\hline & $\Delta \mathrm{C} 2$ & Palacio \\
\hline & $\star \mathrm{C} 3$ & Embajadores \\
\hline \multirow{3}{*}{ 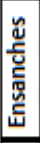 } & E1 & Recoletos \\
\hline & E2 & Argüelles \\
\hline & $+\mathrm{E} 3$ & Chopera \\
\hline \multirow{3}{*}{ 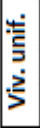 } & v1 & El Viso \\
\hline & V2 & Peñag rande \\
\hline & $\mathrm{V} 3$ & Entrevías \\
\hline \multirow{3}{*}{ 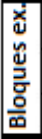 } & B1 & Fuentelarreina \\
\hline & $>\mathrm{B} 2$ & Pinar del Rey \\
\hline & $\star \mathrm{B} 3$ & San Cris tóbal \\
\hline \multirow{3}{*}{ 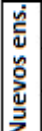 } & $\mathrm{N1}$ & Piovera \\
\hline & $>\mathrm{N} 2$ & Após tol Santiago \\
\hline & $\star \mathrm{N} 3$ & Entrevías (Pozo de Tío Raimundo) \\
\hline
\end{tabular}

Fuente: elaboración propia

Tabla 11. Índice de Diversidad Urbana (IDU) por clase morfológica y nivel socioeconómico del tejido

\begin{tabular}{|l|c|c|c|c|}
\hline Clase morf. & $\begin{array}{c}\text { Superior } \\
(1)\end{array}$ & $\begin{array}{c}\text { Intermediario } \\
(\mathbf{2})\end{array}$ & $\begin{array}{c}\text { Inferior } \\
(3)\end{array}$ & $\begin{array}{c}\text { Media clase } \\
\text { morf. }\end{array}$ \\
\hline Casco (C) & 0,7379 & 1,1052 & 0,8364 & 0,8932 \\
\hline Ensanches (E) & 1,2487 & 0,9305 & 0,6796 & 0,9529 \\
\hline Viv. unif. (V) & 0,7242 & 0,3839 & 0,3478 & 0,4853 \\
\hline Bloques exentos (B) & 0,1883 & 0,3062 & 0,1548 & 0,2164 \\
\hline Nuevos ensanches (N) & 0,4243 & 0,3393 & 0,5765 & 0,4467 \\
\hline Media nivel soc. & 0,6647 & 0,6130 & 0,5190 & 0,5989 \\
\hline
\end{tabular}

Fuente: elaboración propia

De acuerdo con lo que se discutirá en el siguiente apartado, el Índice de Diversidad Urbana, a partir de lo hallado en esta investigación, se correlaciona positivamente con la densidad edificatoria, con la accesibilidad del entorno y con el valor del suelo local. Por eso, no sorprende que los tejidos del casco y de los ensanches dispongan de mayor diversidad funcional, mientras las viviendas unifamiliares y nuevos ensanches presentan valores moderadamente bajos. El tejido E1 (Recoletos) aparece como el más heterogéneo, con un IDU 
de 1,2487, gracias a la gran participación de actividades económicas (comercio, oficinas y actividades de ocio y hostelería) en su composición funcional, que llega a un 35,7\% de la superficie construida (Tabla 6 y Figura 2). Una proporción más equilibrada entre las tres clases de funciones, sin embargo, le confiere al tejido C2 (Palacio), que posee el segundo IDU más elevado (1,1052), la clasificación de polifuncional. Los tejidos excéntricos, con excepción de El Viso (V1) y Pozo de Tío Raimundo (E3), exponen diversidades funcionales notablemente bajas en comparación a los centrales.

\subsection{Correlaciones entre indicadores funcionales}

La Tabla 12 expone las correlaciones halladas entre los indicadores funcionales de los quince tejidos urbanos analizados.

Tabla 12. Correlaciones entre indicadores funcionales. Siglas explicadas en la tabla 3

\begin{tabular}{|c|c|c|c|c|c|c|c|c|c|c|c|c|c|c|}
\hline & & & & & & & cadores fu & cionales & & & & & & \\
\hline & & IDU & $\rho E m p$ & Fecha & $€_{\text {renta }}(t)$ & $€_{\text {viv }}$ & $C V \epsilon_{\text {viv }}$ & $A_{\text {viv }}$ & $\underset{(t)}{\epsilon_{\text {viv }} / \mathrm{m}^{2}}$ & $h_{\text {viv }}$ & gviv & PTP & $L_{t p}$ & $A_{t p}$ \\
\hline & IDU & I & I & I & I & I & / & I & I & I & I & I & I & I \\
\hline & $p \mathrm{Emp}$ & 0,9044 & I & / & / & / & / & / & / & / & / & I & / & / \\
\hline & Fecha & $-0,7427$ & $-0,7835$ & / & / & / & / & / & / & / & / & / & / & / \\
\hline$\frac{\mathscr{d}}{\sigma}$ & $€_{\text {renta }}(t)$ & 0,1647 & 0,4160 & 0,1919 & / & I & / & / & / & / & / & / & / & / \\
\hline$\frac{0}{0}$ & $\epsilon_{\text {viv }}(t)$ & 0,5524 & 0,4889 & $-0,0689$ & 0,7917 & 1 & 1 & 1 & 1 & 1 & 1 & 1 & 1 & 1 \\
\hline$\frac{5}{5}$ & $C \vee \epsilon_{\text {viv }}$ & 0,7721 & 0,5780 & 0,0119 & 0,1339 & 0,4473 & I & 1 & 1 & 1 & 1 & I & 1 & 1 \\
\hline 응 & $A_{\text {viv }}$ & 0,0804 & $-0,0592$ & $-0,0844$ & 0,6922 & 0,7622 & 0,1446 & I & I & I & I & I & I & I \\
\hline$\frac{\pi}{0}$ & $€_{\text {viv }} / \mathrm{m}^{2}(t)$ & 0,6999 & 0,7096 & 0,1553 & 0,7016 & 0,8836 & 0,6068 & 0,4110 & I & / & / & / & / & / \\
\hline & $h_{\text {viv }}$ & $-0,0193$ & $-0,0859$ & $-0,0143$ & 0,5397 & 0,6212 & $-0,1205$ & 0,8962 & 0,2026 & / & I & I & I & I \\
\hline & $g_{\text {viv }}$ & $-0,3657$ & $-0,4214$ & 0,2288 & 0,6305 & 0,3297 & $-0,2472$ & 0,7138 & 0,1498 & 0,6243 & 1 & 1 & 1 & 1 \\
\hline & PTP & 0,4983 & 0,4253 & $-0,3259$ & $-0,1281$ & 0,2213 & 0,5447 & 0,0584 & 0,3781 & $-0,2024$ & $-0,1771$ & I & / & I \\
\hline & $L_{\text {tp }}$ & 0,7138 & 0,8013 & $-0,3868$ & 0,0181 & 0,4170 & 0,5676 & $-0,0134$ & 0,6533 & $-0,1163$ & $-0,3932$ & 0,7343 & / & / \\
\hline & $A_{t p}$ & 0,6555 & 0,7355 & $-0,4145$ & $-0,1528$ & 0,2779 & 0,4450 & $-0,1242$ & 0,4681 & $-0,1205$ & $-0,5158$ & 0,6535 & 0,9371 & 1 \\
\hline Colo & de las c & & & & & & & & & & & & & \\
\hline & Correlación n & dy alta $\pm(0$ & $9-1)$ & & & & & & & & & & & \\
\hline & Correlación a & $a \pm(0,7-0$ & 8999) & & & & & & & & & & & \\
\hline & Correlación n & derada \pm & $0,5-0,69$ & & & & & & & & & & & \\
\hline & Correlación b & $j a \pm(0-0$, & 1999) & & & & & & & & & & & \\
\hline
\end{tabular}

Fuente: elaboración propia

El Índice de Diversidad Urbana (IDU) demuestra correlación positiva muy alta con la densidad potencial de empleados del tejido $(0,9044)$, bien como positiva alta con el coeficiente de variación de los precios de la vivienda $(0,7721)$ y con el número de líneas de transporte público que sirven al entorno del tejido $(0,7138)$, además de correlación negativa alta con la fecha media de construcción de los edificios $(-0,7427)$. El IDU igualmente expone correlaciones positivas moderadas con el precio medio de la vivienda $(0,5524)$, con el precio relativo de la vivienda $(0,6999)$ y con el alcance de las líneas de transporte público $(0,6555)$. 
La densidad potencial de empleados ( $\rho \mathrm{Emp})$ se correlaciona negativa y fuertemente con la fecha media de construcción de los edificios $(-0,7835)$, bien como positiva e intensamente con el precio relativo de la vivienda $(0,7096)$, con el número de líneas de transporte público que atienden el tejido $(0,8013)$ y con su alcance $(0,7355)$. De forma menos marcada, hay correlación moderada positiva entre este indicador con el coeficiente de variación de precios de la vivienda $(0,5780)$.

La renta media anual del hogar en el tejido - $\epsilon_{\text {renta }}(t)$-, como se podría esperar, se relaciona elevada y positivamente con los precios medio $(0,7917)$ y relativo $(0,7016)$ de la vivienda. Por su turno, el coeficiente de variación de los precios de la vivienda $-\mathrm{CV} \in_{\text {viv }}$ - demuestra correlaciones positivas moderadas con el precio relativo de la vivienda $(0,6068)$, con la densidad de paradas o estaciones de transporte público $(0,5447)$ y con el número de líneas de transporte colectivo que sirven al entorno del tejido $(0,5676)$.

El precio relativo de la vivienda en el tejido $-\epsilon_{\text {viv }} / \mathrm{m}^{2}(t)-$ no demuestra correlación significativa con la densidad de paradas o estaciones de transporte público o con el alcance de las líneas que le conectan con el entorno. Hay, de otra parte, correspondencia positiva moderada con el número de líneas $(0,6533)$, pues los tejidos del casco histórico y de los ensanches, así como El Viso (V1) enseñan precios del suelo elevado, así como concentran una red más densa de transportes públicos.

\subsection{Correlaciones entre indicadores morfológicos y funcionales}

La Tabla 13 presenta las correlaciones halladas para los quince tejidos estudiados entre indicadores morfológicos y funcionales.

La proporción de superficie libre total -\%(A-B) - demuestra correlaciones elevadas con la fecha media de construcción de los edificios (0,8670), con la densidad potencial de empleados $(-0,8168)$, con el número de líneas de transporte público $(-0,8273)$, con el alcance de las mismas $(-0,8061)$ y con el Índice de Diversidad Urbana $(-0,7652)$. También existen correlaciones, aunque menos pronunciadas, entre proporción de superficie libre total y densidad de paradas o estaciones de transporte público $(-0,6566)$, coeficiente de variación de precios de la vivienda $(-0,5875)$ y número de plazas de garaje por vivienda en venta $(0,5142)$. La proporción de superficie peatonal _\% $\left(A_{\text {peat }}\right)$-, por otra parte, se relaciona moderada y negativamente con el número de plazas de garaje por viviendas en venta $(-0,5301)$, con el precio relativo de la vivienda en el tejido $(-0,5061)$ y con la densidad de paradas o estaciones de transporte público $(-0,5036)$. 
Tabla 13. Correlaciones entre indicadores morfológicos y funcionales.

Siglas explicadas en las tablas 2 y 3

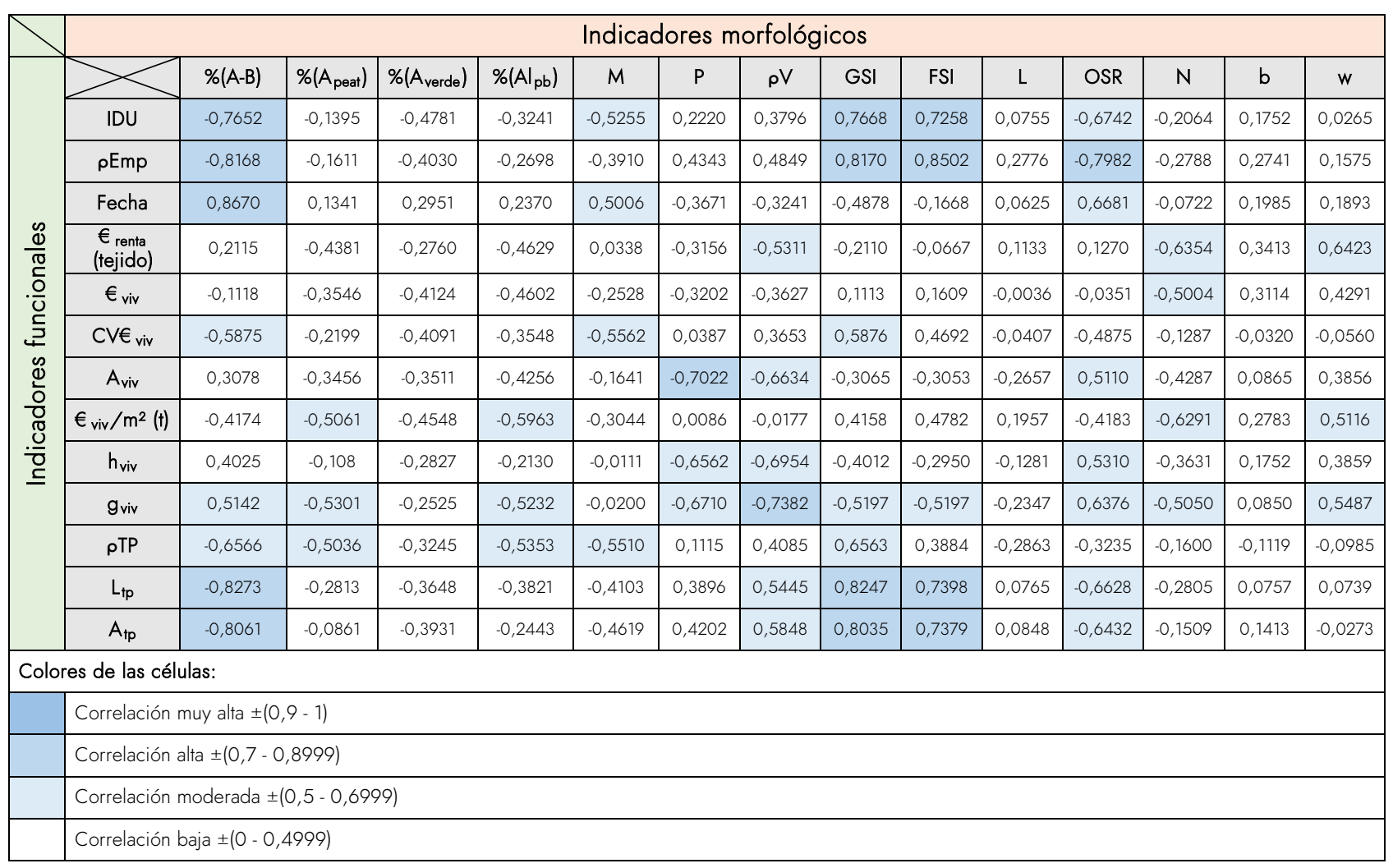

Fuente: elaboración propia

La proporción de superficies libres públicas -\% $\left(A l_{p b}\right)$-, síntesis de las superficies peatonales y de las verdes públicas y fundamental en la percepción de la calidad del entorno urbano demuestra correlaciones moderadas negativas con el precio relativo de la vivienda $(-0,5963)$, con la densidad de paradas o estaciones de transporte público $(-0,5353)$ y con el número de plazas de garaje por vivienda en venta $(-0,5232)$.

La dimensión media de la manzana (M) presenta correlaciones moderadas con el coeficiente de variación de precios de la vivienda $(-0,5562)$, con la densidad de paradas o estaciones de transporte público $(-0,5510)$, con el Índice de Diversidad Urbana $(-0,5255)$, con la relación entre renta y precio relativo de la vivienda $(0,5096)$ y con la fecha media de construcción de los edificios $(0,5006)$.

La población (P) manifiesta correlación alta y negativa con el área útil media de la vivienda (0,7022), bien como moderadas y negativas con el número medio de plazas de garaje por vivienda en venta $(-0,6710)$ y con el número medio de habitaciones $(-0,6562)$. En lo que se refiere a la densidad de viviendas, se han constatado correlaciones moderadas entre este indicador y número medio de habitaciones por vivienda $(-0,6954)$, área media de la vivienda (- 
0,6634), número de líneas de transporte público que atienden al entorno del tejido $(0,5445)$ y su alcance $(0,5848)$ y renta media del tejido $(-0,5311)$. La edificabilidad bruta $-F S I-$, por otra parte, evidencia correlaciones elevadas con la densidad potencial de empleados $(0,8502)$, con el número de líneas de transporte público que atienden a la zona $(0,7398)$ y con su alcance $(0,7379)$ y con el Índice de Diversidad Urbana $(0,7258)$.

El Índice de espacios libres (OSR) es dependiente a la vez de la proporción de superficies libres totales y de la edificabilidad bruta, por eso, tiende a enseñar un comportamiento armonioso con estos indicadores. De esta manera, se le observa una correspondencia elevada con la densidad potencial de empleos $(-0,7982)$ y moderada con el Índice de Diversidad Urbana $(-0,6742)$, con la fecha media de construcción de los edificios $(0,6681)$, con el número de líneas que atienden al entorno del tejido $(-0,6628)$ y con el alcance directo de estas líneas $(-0,6432)$, con el número medio de plazas de garaje por vivienda en venta $(0,6376)$, con el número medio de habitaciones por vivienda ofertada $(0,5310)$ y con el área media de la vivienda $(0,5110)$.

La densidad de la red viaria $(\mathrm{N})$ ostenta correlaciones moderadas con la renta media del tejido $(-0,6354)$, con los precios medios $(-0,5004)$ y relativo $(-0,6291)$ de la vivienda y con el número medio de plazas de garaje por residencia en venta (-0,5050). El ancho de malla (w), por último, se correlaciona moderadamente con la renta media del tejido $(0,6423)$, con el número medio de plazas de garaje por vivienda en venta $(0,5487)$ y con el precio relativo de la vivienda $(0,5116)$.

\section{Discusiones}

En lo que se refiere a los indicadores funcionales, los bloques exentos presentan los menores precios medio y relativo de la vivienda, hecho explicable por la asociación que se hace entre esta forma y los extensos y empobrecidos - en todos los aspectos de la vida urbana- polígonos de promoción o protección oficial construidos a lo largo del siglo XX (Rodríguez-Chumillas, 2001; Rodríguez-Tarduchy, 2011). Por eso, aunque el tejido B1 (Fuentelarreina) cuente con la cuarta más elevada renta, es el séptimo en términos de precio relativo de la vivienda. El casco, por otro lado, demuestra un comportamiento interesante, pues si alberga el menor valor medio de renta, presenta un precio del suelo desproporcionadamente elevado, hecho que repercute en la presión ejercida por el coste de la vivienda en los presupuestos familiares, superior en esta zona de la ciudad. 
El valor medio de la renta anual del hogar es un 108\% superior en el conjunto de tejidos de rango superior con relación al valor medio del grupo intermediario, que, por su turno, es un $56 \%$ más elevado que el del conjunto de rango inferior. Además, la mediana de rentas entre todos los tejidos estudiados es de $33425,50 €$, mientras la media es de 48 303,85 €, lo que demuestra una sobrevaloración de los tejidos más acomodados, indicando la impronta espacial de una desproporcional concentración de renta en las capas sociales superiores. En lo que atañe al comportamiento de los precios de la vivienda con relación al nivel socioeconómico del tejido, se ha encontrado fenómeno similar, con medianas inferiores a las medias $-662813,00 €$ contra $723312,67 €$, respectivamente, en el caso de los precios medios y 4125,90 $€$ contra $4238,13 €$, en el caso de los relativos. De este modo, se constata que existe una tendencia a la supervaloración en los precios inmobiliarios en las categorías residenciales superiores, aunque en proporción menor que lo verificado en cuanto a la concentración de renta, suceso que alivia la presión del coste de la residencia sobre las rentas o presupuestos de las capas sociales superiores (Tabla 14).

\section{Tabla 14. Comparación entre los valores medio y medianos de renta $(\boldsymbol{\epsilon})$ y precios medio} (€) y relativo $\left(€ / \mathrm{m}^{2}\right)$ de la vivienda para los quince tejidos analizados

\begin{tabular}{|l|c|c|c|}
\hline Media & $\begin{array}{c}\text { Renta media } \\
\text { anual del hogar }\end{array}$ & $\begin{array}{c}\text { Precio medio de } \\
\text { la vivienda }\end{array}$ & $\begin{array}{c}\text { Precio relativo } \\
\text { de la vivienda }\end{array}$ \\
\hline Mediana & 38303,85 & 723312,67 & 4238,13 \\
\hline Diferencia & $44,51 \%$ & 662813,00 & 4125,90 \\
\hline
\end{tabular}

Fuente: elaboración propia

Esta constatación corrobora el supuesto teórico de autores como Colby (1933); Hoył (1939); Capel Saez (1975); Harvey (1975); Corrêa (1989); Villaça (2001); Abramo (2009, 2012) en lo que se refiere a los mecanismos de extracción de renta del suelo por medio de la expansión de los sectores residenciales más abonados a lo largo de un eje (o ejes) que promueven una extensión continua de los términos del área urbanizada y en un ritmo más acelerado que en los sectores populares. La incorporación de innovaciones - en el caso madrileño primeramente los ensanches, seguido por las "ciudades-jardín", por los bloques aislados y, finalmente, por los nuevos ensanches, bien como por sus respectivas transformaciones y "evoluciones" a lo largo del tiempo- posibilita la atracción de las familias más pudientes, imponiéndoles un sobreprecio que, sin embargo, no es tan costoso en términos de proporción sobre sus presupuestos si comparado a lo que es para familias menos abonadas. Se puede decir, en síntesis, que la 
obtención de ganancias con base en la exploración del suelo urbanizado -y urbanizable- se basa en mecanismos distintos de acuerdo con la clase social a la que se destina: es una exploración absoluta en los estratos socioeconómicos más elevados, pues ocurre con base en precios absolutos desproporcionadamente elevados; es relativa en los grupos sociales medios y bajos, con base en la inmovilización de un cupo más amplio de su renta para cubrir el coste de la vivienda (extracción de "plusvalías inmobiliarias").

Los datos sobre accesibilidad patentizan que los tejidos más antiguos y centrales son igualmente los más conectados a la red de transportes públicos, suceso notable en lo que atañe al casco histórico, pero aún más perceptible en los ensanches. Corrêa (1989), en ese particular, afirma que a medida que en las grandes ciudades los centros se fueron tornando saturados y los precios del suelo se alzaran rápidamente, no les convenía a ciertas actividades intensivas en espacio y en mano de obra seguir presentes en ese sector. En un primer momento, estas se desplazaron al cinturón periférico del centro, un segmento espacial intermediario entre el centro tradicional y la periferia. Las primeras actividades a lo hacer fueron los terminales de transporte, especialmente a partir de la difusión del ferrocarril, con toda su infraestructura incompatible con los núcleos centrales. En Madrid, este collar "pericentral" coincide con los ensanches tradicionales, bien como con algunos sectores menos alejados de la periferia. En ellos se instalaron las principales estaciones de ferrocarril como Atocha, Delicias, Príncipe Pío la las que se sumaron, más tarde, las estaciones de autobuses Sur, Avenida de América, Moncloa, Plaza Elíptica, entre otras menores), que no tardaran en atraer a sus cercanías dichas actividades que involucran un intenso movimiento de personas.

Para atender a esta necesidad de movilidad de individuos y mercancías, Corrêa (1989) asegura que pronto se constituyen en el anillo "pericentral" los nudos articuladores entre la red de transportes intraurbana e interurbana, suceso que justifica una accesibilidad superior en este entorno con relación a los demás, incluido el centro tradicional. En el caso madrileño, mismo los ensanches más elegantes en torno a Salamanca, aunque atrayendo en menor proporción las comentadas actividades, dispusieron de una suficiente diversidad de funciones y animación de usos, conjuntamente a elevadas densidades, que justifican un grado superior de conexión por transporte público. Asimismo, no se puede olvidar que la accesibilidad, de acuerdo con Villaça (2001), es un elemento clave para la asignación de valor al suelo y maximización de las rentas que le pueden ser extraídas, objetivo primordial que impulsó el proyecto de los ensanches madrileños, haciendo con que a este factor fuera concedida especial atención desde el inicio de los planes (Capel Saez, 1975, 2005). 
Cuando se tiene en cuenta la composición socioeconómica del tejido, se verifica una clara diferencia entre los sectores más centrales y aquellos más periféricos. Los primeros son mejores conectados cuando presentan indicadores socioeconómicos superiores y los peor accesibles tienden a ser los que se encuentran en situación intermediaria (con excepción de los ensanches, con la peor conexión en Chopera - E3). Los tejidos más externos (bloques exentos y nuevos ensanches) enseñan un patrón invertido, pues los más pudientes son abrumadoramente menos conectados (a partir de lo que se infiere una mayor dependencia hacia modos privados de transporte), mientras los de rango social intermediario son los mejores conectados, seguidos con una ligera desventaja por los tejidos del grupo tres, hecho que puede repercutir una mayor dependencia de estas poblaciones hacia el transporte colectivo y una mayor atención a ellas por parte de la administración pública en lo que se refiere a este tema, no obstante esta asistencia parezca reducirse sutilmente junto a los grupos más marginados.

Del análisis sobre la diversidad de usos del suelo (IDU) se puede concluir que los tejidos céntricos del casco histórico y de los ensanches tradicionales son los más variopintos. De hecho, diversos autores están de acuerdo que estas zonas presentan, por su mejor accesibilidad, por las mayores densidades y posibilidades de encuentro e interacciones entre personas, bien como por la herencia de usos que se perpetúan en el tiempo, una animación y diversidad funcional significativamente superiores a las del restante de la ciudad (Corrêa, 1989; Villaça, 2001; Jacobs, 2011; Rodríguez-Tarduchy, 2011). Conforme verificado, hay una correlación negativa elevada entre diversidad urbana y fecha media de construcción de los edificios en Madrid, indicando que cuanto menor esta fecha -es decir, más antiguo el tejido-superior la diversidad. El IDU también se correlaciona positivamente con la accesibilidad y con la densidad constructiva, favoreciendo la diversidad de los sectores más centralizados.

Por otro lado, también se ha encontrado una correlación positiva entre diversidad de funciones y precio -absoluto y relativo- de la vivienda. Conforme se observa en la Figura 2, en los casos del casco histórico, ensanches y viviendas unifamiliares, los tejidos que presentan valores de suelo superiores son los más mezclados, con la excepción de Justicia (C1) -que se constituye en un sector que ha pasado por proceso reciente de gentrificación (Boivin, 2013) - una vez que este tejido no dispone de equipamientos. Palacio (C2), por su turno, dispone de las viviendas más caras, aunque no de los precios relativos más elevados.

Llaman la atención los tejidos de El Viso (V1) y de Pozo de Tío Raimundo (N3) por sus diversidades funcionales superiores a sus homólogos de clase morfológica, a medio camino 
entre los tejidos urbanos "históricos" y los demás. En el primer caso, aunque disponga de una clara predominancia de usos residenciales, presenta valores relativamente altos de funciones económicas $(8,43 \%)$ y de equipamientos $(5,68 \%)$-conforme nos enseñan la Tabla 6 y la Figura 2-, hecho que le confiere un IDU de 0,7242. Eso se debe a su estructura edificatoria de mansiones con excelente calidad constructiva que, aliados a la proximidad con el centro, a una extraordinaria accesibilidad y a una progresiva disponibilidad de su stock residencial (debido a la salida de moradores hacia barrios más recientes), han sido utilizadas para actividades económicas - destacadamente oficinas y clínicas médicas- y equipamientos (escuelas), en un proceso perceptible ya en los años 1970 (Quintana, 1977).

Pozo de Tío Raimundo, ubicado en el barrio de Entrevías, por su turno, dispone de una gama relativamente amplia de actividades económicas (6,84 \%) relacionadas principalmente a los servicios de alimentación, así como a pequeñas tiendas de regalos, estanco, una farmacia, a servicios de peluquería y estética y a un supermercado, además de algunos equipamientos $(3,53 \%)$, de acuerdo con lo verificado en campo, hecho que le confiere un IDU de 0,5765. Este moderado valor presumiblemente se explica por el relativo aislamiento del tejido en relación al entorno urbano y a la baja capacidad económica de los vecinos que, en general no disponiendo de vehículos privados, no se desplazan a otros barrios para las adquisiciones y servicios cotidianos.

Todos los demás tejidos investigados, independientemente de clase morfológica (viviendas unifamiliares, bloques exentos o nuevos ensanches) y del estándar socioeconómico, se hallan en una situación de casi completa oscuridad funcional, siendo clasificados como monofuncionales, de acuerdo con Van den Hoek (2010), y presentando modestas diversidades urbanas, conforme nos enseña la Tabla 12. Se puede concluir, con base en las correlaciones halladas, que eso se debe por una constitución en entornos de gran homogeneidad social y de densidades demográficas y edificatorias- bajas, tornando poco rentables la concentración espacial y la diversificación de actividades. Sorprende específicamente las bajísimas diversidades en la clase de bloques exentos (media de 0,2164), suceso que nos hace concordar con autores como Jacobs (2011) o Rodríguez-Tarduchy (2011), quienes afianzan que esta morfología representa la negación de la ciudad, a partir del punto de vista de que una urbe solamente puede ser constituida con fundamento en la diversidad y en la posibilidad de encuentros insospechados entre personas con distintos modos de vida y necesidades, que hacen uso de una gran variedad de funciones urbanas concentradas en el espacio en distintos horarios del día y de la noche (Jacobs, 2011). 
En lo referente a las correlaciones entre indicadores funcionales, la relación consistente entre diversidad funcional (IDU) y densidad de empleados se explica, pues cuanto más elevada aquella mayor la proporción de actividades económicas y de equipamientos en relación al predominante uso residencial, conllevando a una más destacada dinámica de empleos. Por eso, los tejidos más diversos del casco histórico y de los ensanches suponen una densidad de empleos más elevada, lo inverso ocurriendo en tejidos menos diversos como de los bloques exentos o de viviendas unifamiliares (Tabla 6).

Igualmente, se concluye que zonas más antiguas de Madrid encierran más elevada diversidad urbana, no existiendo, evidentemente, una relación de causa y efecto entre diversidad y edad del entorno, pero un vínculo mediatizado por otros factores, ya que los tejidos más añejos son más centrales, más accesibles y disponen de mayor diversidad social. Eso lo demuestra las correlaciones entre IDU, coeficiente de variación de precios de las viviendas y alcance de las líneas de transporte público. Entornos más mezclados socialmente cuentan con una diversidad más amplia de modos de vida e intereses personales o grupales, exigiendo una gama más vasta de servicios, conforme ya apuntaba Jacobs (2011). Por eso, los tejidos del casco y de los ensanches, más diversos socialmente, lo son también funcionalmente, en cuanto los demás presentan las dos diversidades en niveles bajos. Aquellos son igualmente los tejidos que exponen proporción más elevada de usos destinados a actividades económicas y equipamientos y un más elevado potencial de empleabilidad (densidad estimada de empleos). Asimismo, tejidos más accesibles por transporte público (con destaque a los ensanches y, en segundo lugar, al casco histórico) también ven potenciada su diversidad funcional.

Estas zonas social y funcionalmente más heterogéneas están asociadas a suelos más valorizados, conforme demuestran las correlaciones entre renta media del hogar y precios medio y relativo de la vivienda. En otras palabras, se puede decir que, con base en la muestra estudiada, en Madrid la segregación socioespacial impuesta - aquella que limita la capacidad de elección familiar del lugar de residencia en función de una disincronía entre su capacidad financiera y el valor del suelo - es más notoria que la autosegregación- separación y concentración voluntarias por parte de grupos sociales de mayor capacidad financiera en entornos espaciales limitados (Corrêa, 1989).

Realidad bastante consistente en los tejidos "históricos" del casco y de los ensanches, bien como en las viviendas unifamiliares, esta correspondencia se turba en los entornos exclusivos (autosegregados) vinculados a las clases de bloques exentos y nuevos ensanches. De este modo, 
como se observa en la Tabla 6, Fuentelarreina (B1) es un tejido poco diverso socialmente (coeficiente de 0,25), no obstante disponga de suelo relativamente valorizado $\left(4234,84 € / \mathrm{m}^{2}\right)$. Lo mismo pasa en Piovera (N1), tejido poco diverso $(0,31)$ y muy valorizado $\left(5123,49 € \in \mathrm{m}^{2}\right)$. Finalmente, la relación positiva entre diversidad social y accesibilidad es inferior a la existente entre aquel indicador y el valor del suelo, aunque expresiva. Por eso, los entornos mejor integrados al sistema de transporte público (casco histórico, ensanches y parte de viviendas unifamiliares) son los más diversos, en tanto otros, más aislados, demuestran menores diversidades o mezcla social.

Las correlaciones entre indicadores morfológicos y funcionales demuestran que entornos más abiertos - profusos en espacios libres públicos o privados-, ligados a los tejidos modernos de viviendas unifamiliares, bloques exentos y nuevos ensanches presuponen menor riqueza de usos y mayor homogeneidad funcional, mientras los tejidos "históricos" (casco y ensanches), más colmados, son los más diversos funcionalmente, hecho que se refleja en una mayor variedad de actividades económicas y de usos destinados a equipamientos y, por tanto, en una más elevada densidad potencial de empleos. Además, los tejidos más abiertos, en general más periféricos, son también aquellos menos comunicados por el sistema de transportes públicos. En este punto, conviene destacar que las más vastas superficies peatonales se ubican en estas promociones periféricas, destacadamente en los bloques exentos y nuevos ensanches de carácter popular (San Cristóbal, B3 y Pozo de Tío Raimundo, N3). Son vecindarios con valor de suelo bajo, que cuentan con una menor proporción de plazas privadas de aparcamiento y, por su carácter excéntrico, disponen de una red de transportes públicos menos densa.

Las correlaciones negativas entre dimensión media de la manzana, diversidades funcional y social y densidad de paradas o estaciones de transporte público están, en el caso madrileño, en línea con Jacobs (2011), quien, en los años 1960, ya afirmaba que manzanas menores generan una trama más densa, mayor posibilidad de recorridos, invitan a la exploración peatonal y al encuentro entre personas, y exponen de modo más eficaz los pequeños y medianos negocios, favoreciendo la diversificación de usos espaciales. Escapa a esta tendencia el tejido de Recoletos (E1), con grandes manzanas (en media $10343,08 \mathrm{~m}^{2}$ ) y la mayor diversidad urbana $(1,2487)$, en función de otros fatores como su prestigio histórico, elevadas densidades, excelente accesibilidad y rentas elevadas. En contraste, las manzanas más menudas ocurren en entornos más antiguos (casco histórico) y donde el cupo de presupuestos familiares vinculados a los costes de la vivienda son menores (grupos más acomodados), conforme indican las 
correlaciones entre dimensión media de las manzanas y edad de los edificios y relación entre renta y coste relativo de la vivienda, respectivamente.

Por fin, y no menos importante, se verifica en Madrid que sectores más densos en términos residenciales (viviendas/Ha) se configuran por características socioeconómicas de rango inferior y con viviendas menores. En este punto conviene destacar las correlaciones entre densidad de viviendas y accesibilidad: se ha comprobado que entornos más densos son más accesibles, sirviéndose por mayor número de líneas de transporte público, que, por su turno, suman un alcance más significativo. De modo distinto, entornos más densos en términos de edificabilidad (FSI) coinciden con los más diversos funcionalmente, representados por los tejidos del casco histórico y, sobre todo, de los ensanches, también con excelente accesibilidad por transportes públicos. En este caso, existe una correlación no significativa - aunque no despreciable - entre densidad edificatoria, precio relativo de la vivienda y coeficiente de variación de precios de la vivienda, alrededor de 0,47, indicando que, con matices y diversas excepciones, hay proclividad a que los tejidos más densos posean suelos más caros y sean más diversos socialmente. Vinculada a la densidad del ambiente construido está la de la malla viaria (incluidos caminos peatonales y carriles bici). Las correlaciones entre este indicador y los indicadores socioeconómicos indican que una malla más menuda tiende a vincularse a entornos con suelo menos caro y de hogares menos acomodados, gracias al patrón de manzanas cerradas o privatizadas de los modernos tejidos destinados a rentas más elevadas, y, por otro lado, de manzanas abiertas y permeables en polígonos modernistas y "posmodernistas" de cualidad más popular.

\section{Conclusiones}

Con el objetivo de investigar cuantitativamente los resultados funcionales de la producción desigual del espacio urbano madrileño y sus relaciones con la morfología urbana, este trabajo se fundamentó en la selección de 22 indicadores morfológicos y veinte funcionales en una muestra de quince tejidos urbanos, siendo tres en cada clase morfológica abordada por RodríguezTarduchy (2011), el primer coincidiendo con el contenido socioeconómico de rango superior en el ámbito de su clase, el segundo de rango intermediario, y el tercer, inferior. Los análisis se basaron en una combinación de las metodologías propuestas por Pont y Haupt (2009), Van den Hoek (2010) y Solís-Trapero et al. (2019) y posibilitaron conclusiones cuantitativas, de modo a que fuera contestada la indagación sobre cómo, con base en la muestra estudiada, las formas y 
las funciones urbanas (o usos del suelo) se influyen mutuamente y cómo cada característica funcional puede relacionarse con las demás.

Las correlaciones demostradas indican que los polígonos residenciales que plasmaron los ideales modernistas de baja densidad y segregación funcional promovieron una reducción en las diversidades social y funcional de los nuevos espacios urbanos madrileños, destacadamente en los entornos socioeconómicos más modestos, menguando lo que Jacobs (2011) y Holanda (2012) califican por urbanidad y descomponiendo la tradición mediterránea de ciudad compacta y diversa. Urge en las metrópolis contemporáneas, incluso en el contexto español, la implantación de políticas que garanticen la mezcla de funciones disfrutadas por distintos segmentos sociales en un espacio de algunas hectáreas, conteniendo edificios plurifamiliares con usos terciarios en los bajos - posibilitando una densificación con diversificación funcional-, implantados en manzanas suficientemente menudas para proporcionar la invitación a la caminata y al encuentro entre personas (diversas). En síntesis, el método expuesto y desarrollado ha demostrado su adecuación para un examen crítico sobre cómo se interrelacionan formas y funciones urbanas en el ámbito urbano europeo y, más precisamente, en el español.

Declaración responsable: El autor declara que no existe conflicto de interés en lo que se refiere a la publicación de este artículo. 


\section{Bibliografía}

Abramo, P. (2009). La ciudad calidoscópica. Apuntes del CENES, XXVIII(48), 125-196. Retrieved from https: / / dialnet.unirioja.es/servlet/articulo?codigo=3399342.

Abramo, P. (2012). La ciudad com-fusa: mercado y producción de la estructura urbana en las grandes metrópolis latinoamericanas. Eure, XXXIIII(114), 3569. http://dx.doi.org/10.4067/S0250-71612012000200002.

Alguacil, J., De la Fuente, R., Martínez, M. A., Ubrich, T., \& Velasco González, M. (2011). Madrid. In: Políticas urbanas en España: grandes ciudades, actores y gobiernos locales (pp. 105141). Barcelona: Icaria editorial.

Amat Rodrigo, J. (2016). Correlación lineal y Regresión lineal simple. In Ciencia de Datos. Retrieved from

https://www.cienciadedatos.net/documentos/24_correlacion_y_regresion_lineal.

Ayuntamiento de Madrid (2016). Cartografía municipal por distritos a escala 1:1.000, formato SHP, ETRS89. In Conjunto de datos. Retrieved from https://datos.madrid.es/portal/site/egob/menuitem.c05c1f754a33a9fbe4b2e4b284f1a5 a0/?vgnextoid=a4f36d34fa86c410VgnVCM2000000c205aOaRCRD\&vgnextchannel=374512b 9ace9f310VgnVCM100000171f5aOaRCRD, fecha de consulta: 09-01-2020.

Ayuntamiento de Madrid (2018a). Demografía y población: Censos de población. In: Áreas de Información Estadística. Retrieved from

https://www.madrid.es/portales/munimadrid/es/Inicio/El-Ayuntamiento/Estadistica/Areas-deinformacion-estadistica/Demografia-y-poblacion/Censos-de-Poblacion/.

Ayuntamiento de Madrid (2018b). Edificación y vivienda: Mercado de la vivienda. In: Áreas de Información Estadística. Retrieved from

https://www. madrid.es/portales/munimadrid/es/Estadistica/Areas-de-Informacion-

Estadistica/Edificacion-y-

Vivienda? vgnextfmt=detNavegacion\&vgnextchannel=82872676d94b4210VgnVCM2000000c2 $\underline{05 a 0 a R C R D}$

Blanco, I., \& Subirats, J. (2012). Políticas urbanas en España: dinámicas de transformación y retos ante la crisis. Geopolítica(s), III(1), 15-33. http://dx.doi.org/ 10.5209/rev_GEOP.2012.v3.n1.39304 
Brandis, D. (1983). El paisaje residencial en Madrid. Madrid: Comunidad de Madrid, Dirección General de Acción Territorial y Urbanismo.

Conzen, M. R. (1960). Alnwick, Northumberland: a study in town-plan analysis. Hoboken: Wiley.

Capel Saez, H. (1975). Capitalismo y morfología urbana en España ( $1^{\text {st }}$ ed.). Barcelona: Asenet.

Capel Saez, H. (2005). La morfología de las ciudades: sociedad, cultura y paisaje urbanos (v. 1), ( $1^{\text {a }}$ ed.). Barcelona: Ediciones del Serbal.

Corrêa, R. L. (1989). O espaço urbano (1 ${ }^{\text {st }}$ ed.). São Paulo: Ática.

Colby, C. C. (1933). Centrifugal and centripetal forces in Urban Geography. Annals of the Association of American Geographers, XXIII(1), 1-20. https://doi.org/10.4157/grj.9.736.

Empresa Municipal de Transportes de Madrid (EMT Madrid) (2015) Navega por Madrid. Retrieved from https://www.emtmadrid.es/EMTBUS/NavegaporMadrid.

Fotocasa (2020). Comprar viviendas en Madrid. Retrieved from https://www.fotocasa.es/es/comprar/viviendas/madrid-provincia/madrid-zonade/m? combinedLocationlds $=724,14,28,173,0,0,0,0,0$.

Harvey, D. (1975). Class structure in a capitalistic society and the theory of residential differentiation. In R. F. Peel, M. Chisholm \& P. Haggett (Coords.), Processes in Physical and Human Geography (1 ${ }^{\text {st }}$ ed.) (pp. 354-369). London: Heinemann.

Harvey, D. (1982a). O trabalho, o capital e o conflito de classes em torno do ambiente construído nas sociedades capitalistas avançadas. Espaço e debates, II(6), 6-35. Retrieved from https://antropologiadeoutraforma.files.wordpress.com/2014/03/david-harvey-o-trabalhoo-capital-e-harvey-david-o-conflito-de-classes-em-torno-do-ambiente-construc3addo-nas-sociedadescapitalistas-avanc3a7adas.pdf.

Harvey, D. (1982b). The limits to capital ( $1^{\text {st }}$ ed.). Oxford: Basil Blackwell Publisher Limited.

Hernández Aja, A. (1997). Metodología de determinación de ámbitos y parámetros. In: Hernández Aja, A. (Coord.). La ciudad de los ciudadanos (1 ${ }^{\text {st }}$ ed.) (pp. 119-135). Madrid: Dirección General de la Vivienda, la Arquitectura y el Urbanismo.

Holanda, F. (2012). Urbanidade: arquitetônica e social. In D. Aguiar (Coord.), Urbanidades (pp. 163-188). Rio de Janeiro: Folio Digital.

Hoyt, H. (1939). The structure and growth of residential neighbourhoods in American cities $\left(1^{\text {st }}\right.$ ed.). Washington D. C.: United States Government Printing Office. 
Idealista (2020). 23.484 casas y pisos en Madrid. Retrieved from https://www.idealista.com/venta-viviendas/madrid-madrid/.

Instituto Nacional de Estadística (2019). Atlas de distribución de renta de los hogares. In: Estadística Experimental. Retrieved from https://www.ine.es/jaxiT3/Tabla.htm?t=31097.

López de Lucio, R. (1995). La recuperación de una forma urbana clásica: revisión crítica de una experiencia y análisis comparado de datos. In R. López de Lucio \& A. Hernández Aja, Los nuevos ensanches de Madrid: la morfología residencial de la periferia reciente, 1985-1993 ( $1^{\text {st }}$ ed.) (pp. 15-83). Madrid: Gerencia Municipal de Urbanismo del Ayuntamiento de Madrid.

López de Lucio, R. (2003). Transformaciones territoriales recientes en la región urbana de Madrid. Urban, VIII, 124-161.

Metro Madrid (2019). Planos. Retrieved from https://www.metromadrid.es/es/viaja-enmetro/plano-de-metro-de-madrid.

Ministerio de Hacienda (2019). Sede Electrónica del Catastro. Retrieved from https://www.sedecatastro.gob.es/

Naredo, J. M. (2010). El modelo inmobiliario español y sus consecuencias. Boletín $C F+F$, (44). Retrieved from http://habitat.aq.upm.es/boletin/n44/ajnar.html.

Panerai, P. R., Castex, J., \& Depaule, J. (1986). Formas urbanas: de la manzana al bloque. Barcelona: Editorial Gustavo Gili, S. A.

Pont, M. B., \& Haupt, P. (2009). Space, density and urban form (1 ${ }^{\text {st }}$ ed.). Delft: Delft University of Technology.

Red Nacional de los Ferrocarriles Españoles (2019). Cercanías Madrid: Estaciones y líneas. Retrieved from http://www.renfe.com/viajeros/cercanias/madrid/lineas/index.html.

Roch Peña, F. (2009). Morfología, deterioro urbano y precio de la vivienda en Madrid, Ciudades, (12), 171-196. https://doi.org/10.24197/ciudades.12.2009.171-196.

Rodríguez-Chumillas, I. (2001). Vivienda y promoción inmobiliaria en Madrid. Lleida: Universitat de Lleida.

Rodríguez-Tarduchy, M. J. (2011). Forma y ciudad: en los límites de la Arquitectura y el Urbanismo. Madrid: Cinter Divulgación Técnica SLL. 
Rubiera Morollón, F., Pérez Rivero, J. L., \& González Marroquín, V. (2016). Urban sprawl in Spain: differences among cities and causes, European Planning Studies, XXIV(1), 207226. https://doi.org/10.1080/09654313.2015.1080230.

Sequera Fernández, J. (2013). Las políticas de la gentrificación en la ciudad neoliberal. Nuevas clases medias, producción cultural y gestión del espacio público: el caso de Lavapiés en el centro histórico de Madrid. Madrid: Universidad Complutense de Madrid.

Solís Trapero, E., Ruiz-Apilanéz, B., Camacha Gutiérrez, I. G., Ureña Francés, J. M., \& Mohíno Sanz, I. (2019). El enfoque morfogenético y cuantitativo aplicado al estudio de las formas urbanas y la diversidad de usos: el caso de Toledo, Boletín de la Asociación de Geógrafos Españoles, LXXXII(2753), 1-45. https://doi.org/10.21138/bage.2753.

Tamayo Palacios, A. (2011). Exclusión social en la Madrid del desarrollismo: la influencia del modelo inmobiliario de venta de viviendas a gran escala durante el proceso de construcción del área metropolitana de Madrid en la cohesión social de la ciudad, Revista Invi, XXVI(73), 73102. http://dx.doi.org/10.4067/S0718-83582011000300003.

Tomàs, M. (2011). La escala metropolitana: un análisis transversal. In: Políticas urbanas en España: grandes ciudades, actores y gobiernos locales (pp. 283-305). Barcelona: Icaria editorial. Van den Hoek, J. (2010). The Mixed Use Index (MXI) as planning tool for (new) towns in the 21st century. In International New Town Institute (Coord.), New towns for the 21st century (1 $1^{\text {st }}$ ed.) (pp. 198-207). Amsterdam: Sun.

Villaça, F. (2001). Espaço intra-urbano no Brasil (2 $2^{\text {nd }}$ ed.). São Paulo: Studio Nobel; FAPESP; Lincoln Institute. 